N 6938075

NASA CR -72590

\title{
CREEP OF COO SINGLE CRYSTALS
}

by

A. H. Claver, M. S. Seltzer, and B. A. Wilcox Metal Science Group

prepared for

NATIONAL AERONAUTICS AND SPACE ADMINISTRATION RESEARCH GRANT NGR-36-002-070

on

HIGH TEMPERATURE OXIDATION OF ALLOYS:

COBALT-CHROMIUM BASE ALLOYS

September 29,1969

BATTELLE MEMORIAL INSTITUTE

Columbus Laboratories

505 King Avenue

Columbus, Ohio 43201 
CREEP OF COO SINGLE CRYSTALS

by

A. H. Clauer, M. S. Seltzer, and B. A. Wilcox Metal Science Group

prepared for

NATIONAL AERONAUTICS AND SPACE ADMINISTRATION

Research Grant NGR-36-002-070

on

HIGH TEMPERATURE OXIDATION OF ALLOYS :

COBALT-CHROMIUM BASE ALLOYS

September 29, 1969

BATTELLE MEMORIAL INSTITUTE

Columbus Laboratories 505 King Avenue

Columbus, Ohio 43201 


\section{TABLE OF CONTENTS}

$\underline{\text { Page }}$

INTRODUCTION . . . . . . . . . . . . . . . . . . . . . . . 1

EXPERIMENTAL PROCEDURE . . . . . . . . . . . . . . . . . . . . . . 2

Creep Specimens . . . . . . . . . . . . . . . . . . 2

Creep Testing . . . . . . . . . . . . . . . . . . 2

Structural Studies .................... . 4

Optical Metallography ................. 4

Transmission Electron Microscopy (TEM) . . . . . . . . . 4

RESULTS . . . . . . . . . . . . . . . . . . . . . . . . 4 4

Creep Properties . . . . . . . . . . . . . . . . . 5

Deformation Mode ..................... . . 11

Creep Substructure . . . . . . . . . . . . . . . . . 13

DISCUSSION . . . . . . . . . . . . . . . . . . . . 15

Substructure ..... . . . . . . . . . . . . . . . 23

Relevance of Creep Results to Oxidation Behavior . . . . . . . . 24

CONCLUSIONS . . . . . . . . . . . . . . . . . . . . . 28

ACKNOWLEDGMENTS . . . . . . . . . . . . . . . . . . . . . . 29

REFERENCES . . . . . . . . . . . . . . . . . . . . . . 30 


\section{LIST OF TABLE CAPTIONS}

Page

TABLE 1. TRANSVERSE DIMENSIONS AND STRAIN DISTRIBUTION

ALONG SPECIMEN GAGE LENGTH AFTER CREEP . . . . . . . . . . . 6

TABLE 2. SUMMARY OF CREEP DATA FOR COO SINGLE CRYSTALS . . . . . . . 8

TABLE 3. THE STRESS EXPONENT, $n$, AND ACTIVATION ENERGIES

FOR THE CREEP RATE, $\dot{\epsilon}_{2}$, DIFFUSION AND DISLOCATION

GLIDE IN MATERIALS HAVING AN S-SHAPED CREEP CURVE . . . . . . 20 


\section{LIST OF FIGURE CAPTIONS}

Figure 1. Procedure by Which the Creep Specimens were Machined from As-Received Single Crystal Boules

Figure 2. Compression Creep Furnace for Creep Testing in Controlled Atmospheres

Figure 3. Schematic of a Typical Compression Creep Curve of CoO Single Crystals Having a $<100>$ Compression Axis. Stages 1 and 2 were actually observed in creep tests. See text for discussion of Stage 3 .

Figure 4. Temperature Dependence of $\dot{\varepsilon}_{2}$ at Two Oxygen Pressures

Figure 5. The Stress Dependence of $\dot{\varepsilon}_{2}$ at 1 Atmosphere of Oxygen

Figure 6. The Dependence of $\dot{\varepsilon}_{2}$ on the Partial Pressure of Oxygen

Figure 7. Composition Dependence of $\dot{\varepsilon}_{2}$ at $850 \mathrm{psi}$ and $1100^{\circ} \mathrm{C}$

Figure 8. Precipitate Distribution in a CoO Single Crystal Annealed 66 Hours in One Atmosphere of Oxygen Followed by a Water Quench; $850 \mathrm{X}$

Figure 9. CoO Single Crystal Annealed 66 Hours at $1100^{\circ} \mathrm{C}$ in an Argon-0xygen Atmosphere having $\mathrm{P}_{\mathrm{O}_{2}}=10^{-4} \mathrm{~atm}$, followed by a Water Quench

a. Near the Center of the Specimen; $1000 \mathrm{X}$.

b. Near the Edge of the Specimen; $1000 \mathrm{X}$.

Figure 10. Slip Bands on an Atypical Specimen that Deformed Predominantly by Slip on One Slip System; $9 \mathrm{X}$
a. (100) view
b. (010) view

Figure 11. Precipitate Particles in $\mathrm{CoO}$ and the Dislocation Debris Associated with them

a. As-Received Microstructure of CoO Single Crystals. The white precipitates are probably $\mathrm{Co}_{3} \mathrm{O}_{4}$; polished and etched; $850 \mathrm{X}$.

b. $\mathrm{Co}_{3} \mathrm{O}_{4}$ Particle Observed by Transmission Electron Microscopy.

Figure 12. Sub-boundaries Decorated with $\mathrm{Co}_{3} \mathrm{O}_{4}$ Particles after Creep at a High Stress, $1700 \mathrm{psi}$, and $1000^{\circ} \mathrm{C}$ in a $1.0 \mathrm{~atm}$ Oxygen Atmosphere. The total creep strain was $7.9 \%$.

Figure 13. A $\{100\}$ Surface Containing Two Sets of Sub-boundaries Decorated with $\mathrm{Co}_{3} \mathrm{O}_{4}$ Precipitates. The specimen was creep tested at $1100^{\circ} \mathrm{C}$ and $930 \mathrm{psi}$ in a 1.0 atm oxygen atmosphere. The total creep strain was $8.6 \%$. 
Figure 14. Polished Sections Through the Specimen in Figure 10. The precipitates do not indicate any significant pattern of substructure

Figure 15. Two Types of Sub-boundaries Observed in $\mathrm{CoO}$ after Creep

a. Creep tested at $1000^{\circ} \mathrm{C}$ and $1700 \mathrm{psi}$ in 1 atm oxygen to 0.0815 creep strain.

b. Creep tested at $1048^{\circ} \mathrm{C}$ and $850 \mathrm{psi}$ in 0.01 atm oxygen to 0.077 creep strain. The misorientation across the boundary is $0.4^{\circ}$ around $[100]$.

Figure 16. Representation of How Stress and Composition can Influence Creep of Adherent CoO Scales at Temperature; i.e., during Oxidation 


\section{ABSTRACT}

CoO single crystals having a $<100>$ axial orientation were creep tested in compression at oxygen pressures of $\mathrm{p}_{\mathrm{O}_{2}}=10^{-4}$ atm to 1 atm. Tests were conducted over a temperature range of 1000 to $1200^{\circ} \mathrm{C}\left(0.60-0.71 \mathrm{~T}_{\mathrm{m}}\right)$ and a stress range of 850 to 1700 psi. Sigmoidal (S-shaped) creep curves were observed. The dependence of the creep rate, $\dot{\varepsilon}_{2}$, at the inflection of the creep curve on temperature, stress and oxygen pressure was investigated. It was found that $\dot{\epsilon}_{2} \propto \mathrm{p}_{\mathrm{O}_{2}}^{0.48} \sigma^{6.8} \exp -\left(\mathrm{Q}_{\mathrm{c}} / \mathrm{RT}\right)$, where $\mathrm{Q}_{\mathrm{c}}=99.8 \mathrm{kcal} / \mathrm{mol}$ at $\mathrm{p}_{\mathrm{O}_{2}}=1$ atm and $87.1 \mathrm{kcal} / \mathrm{mol}$ at $\mathrm{p}_{\mathrm{O}_{2}}=10^{-2}$ atm. These activation energies for creep suggest that the creep rate, $\dot{\varepsilon}_{2}$, is controlled by oxygen diffusion.

The operative slip systems were $\{110\}<110>$. The creep substructure was studied by decoration of sub-boundaries by $\mathrm{Co}_{3} \mathrm{O}_{4}$ precipitate particles and by transmission electron microscopy. Regular arrays of sub-boundaries formed during creep. A significant fraction of these appeared to be tilt boundaries.

The creep data obtained here were used to develop a qualitative picture of how CoO scales may creep during isothermal oxidation of Co. 


\title{
CREEP OF COO SINGLE CRYSTALS
}

by

\author{
A. H. Clauer, M. S. Seltzer, and B. A. Wilcox \\ Battelle Memorial Institute \\ Columbus Laboratories \\ Columbus, Ohio 43201
}

\section{INTRODUCTION}

Creep is an important factor in determining the ability of an oxide scale to remain mechanically sound during high temperature oxidation. The oxide scale forming at elevated temperatures is usually subjected to increasing mechanical stresses as it thickens. The capacity of the scale to deform plastically to relieve these mechanical stresses before they cause the oxide to crack or to lose adhesion to the metal is an important factor controlling the soundness of the scale.

Grain size, purity, environment, stoichiometry, dispersions of other phases, and porosity al1 have a significant influence on the creep properties of protective oxides. However, the interpretation of operative creep mechanisms and the way in which the above-mentioned parameters influence the mechanisms in specific oxides is still speculative and based on rather tenuous experimental evidence.

Oxide scales are quite nonuniform in microstructure and attempts to measure the creep properties of oxide scales are fragmentary $(1-3)$ and difficult to interpret. A more reasonable approach is to control the experimental variables as closely as possible by studying pure, single-crystal and polycrystalline oxides first. In this way the defect concentration, grain size, and porosity are much more easily controlled and their relative contributions to the creep behavior can be determined. 
This study was undertaken to determine some of the pertinent factors controlling creep of $\mathrm{CoO}$, including stoichiometry, temperature and stress. This oxide forms during oxidation of Co-base alloys and its plasticity and adherence may affect the oxidation behavior. Single crystals were used to eliminate the influence of grain boundaries, which can be very important in the creep of oxides. Polycrystalline $\mathrm{CoO}$ is being studied at present, and the results will be discussed in a later report.

EXPERIMENTAL PROCEDURE

\section{Creep Specimens}

Two cobalt monoxide single crystal boules, grown by the flame fusion technique, were obtained from Marubeni-Iida (America), Inc. The boules had a [100] axial orientation and a typical manufacturers analysis (in weight \%) was: Co, $79.70 \%$; Fe, $0.085 \% \max$; Cu, trace; $\mathrm{Mn}, 0.002 \% \max ; \mathrm{C} 1,0.004 \% \max ; \mathrm{SO}_{4}$, $0.006 \% \max ; \mathrm{Pb}$ and other heavy metals, $0.0002 \% \max$.

Each boule was oriented by Laue back reflection and was then sectioned parallel to the (100) plane as shown in Figure 1 using a diamond cutoff wheel. Cylindrical creep specimens having a [100] axial orientation were ultrasonically trepanned from each section. After machining, the specimens were cleaned in methyl ethyl ketone and the end faces of the specimens were ground parallel on \#600 SiC paper.

\section{Creep Testing}

Creep experiments were performed in compression under a controlled atmosphere. Figure 2 shows a schematic of the apparatus design. The furnace, 
with heating elements of Super Kanthal $\left(\mathrm{MoSi}_{2}\right)$ was controlled to within $\pm 2{ }^{\circ} \mathrm{C}$ and the temperature gradient along the specimen was less than $1^{\circ} \mathrm{C}$. The specimen was located in an alumina muffle tube which was sealed at both ends by water cooled ' $O$ ' ring seals and bellows arrangements. The gas providing the controlled atmosphere flowed continuously during the creep test. The flowing gases, consisting of air, pure oxygen, or argon-oxygen mixtures obtained commercially, were dried by passing them through Drierite.

The loading platens in contact with the ends of the compression specimens were alumina, as were the loading ram and pedestal. Although no indentation of the loading platens by the specimen was ever detected, the platens were replaced after every test. Sheets of 0.001 inch thick platinum foil were placed between the specimen ends and the alumina in order to inhibit interaction between the $\mathrm{CoO}$ and $\mathrm{Al}_{2} \mathrm{O}_{3}$. This foil could be peeled off after the creep tests indicating very little or no interaction between the $\mathrm{CoO}$ specimen, platinum foil and alumina platens.

Specimens were loaded directly through the top loading ram and the stress was maintained constant by adding the appropriate weights at $0.2 \%$ creep strain intervals. The lower alumina pedestal was fixed to the creep frame, and the upper alumina loading ram was joined to a water-cooled stainless steel ram at the top of the muffle. The upper load train was rigidly aligned, by a set of linear bearings as shown in Figure 2 .

Creep strain was recorded continuously during the creep test using a linear variable differential transducer (IVDT) to detect the difference in the deflection between the bottom of the lower platen and the bottom of the upper platen (Figure 2). This arrangement provided a sensitivity of $\pm 60 \mu$ in. No creep of the alumina push rods was observed at the highest temperature studied, $1200^{\circ} \mathrm{C}$. 


\section{$\underline{\text { Structural Studies }}$}

\section{Optica1 Meta1lography}

Only surfaces paralle1 to a $\{100\}$ plane were examined. Creep specimens were cleaved on $\{100\}$ planes parallel to the compression axis. The specimens were then mounted and mechanically ground and polished, finishing with Linde B and microcloth. Most of the structural studies were made on the as-polished surfaces. Etch pitting studies were also made but the precipitation of a second phase, $\mathrm{Co}_{3} \mathrm{O}_{4}$, on cooling from the creep temperature modified the substructure formed during creep. Therefore this technique was not used extensively.

Transmission Electron Microscopy (TEM)

Thin foils for TEM were prepared from creep tested specimens by first cleaving slabs on $\{100\}$ planes parallel to the compression axis. The slabs were ground to 0.020 inch thickness and were subsequently jet indented chemically in $\mathrm{H}_{2} \mathrm{PO}_{4}$ maintained at 70 to $80^{\circ} \mathrm{C}$. The thin areas at the periphery of the hole in the indented slab were then examined by TEM. Additional details of thin foil preparation are given in reference (4).

\section{RESULTS}

Creep tests were conducted in compression on CoO single crystals having a $<100>$ axial orientation over a temperature range of 1000 to $1200^{\circ} \mathrm{C}$ and a stress range of 850 to $1700 \mathrm{psi}$. The creep tests were performed in atmospheres having controlled partial pressures of oxygen ranging from $1 \mathrm{~atm}$. to $10^{-4} \mathrm{~atm}$. These were obtained using oxygen, air, or commercial argon-oxygen mixtures. 
The specimens were creep tested to only about $8 \%$ strain because barreling of the specimen became significant at higher creep strains and made it impossible to maintain constant stress during creep. The cross-sections assumed an elliptical shape during creep, with one diameter showing no change in dimension and the diameter perpendicular to it showing the maximum increase in dimension. Table 1 shows how the transverse dimensions and the creep strain varied along the gage length of a typical specimen. An elliptical cross-section was assumed in calculating the cross-sectional area after creep. After $8 \%$ creep strain, the strain in the center of the gage length was about $50 \%$ larger than the tota1 compressive strain, causing the true stress in this region to decrease to 0.95 of the initial stress. Hence in the region of the gage length where most of the creep was produced, the stress decreased continuous $1 \mathrm{y}$ during the test, and at higher creep strains, as barreling became more pronounced, this condition became more unfavorable. At low creep strains, where barreling was not as pronounced, the stress was assumed to be constant during the creep test.

\section{Creep Properties}

The creep curves did not have the classic shape, defined by a primary creep region of decelerating creep followed by a steady state region of constant creep rate. Instead, the creep curves were sigmoidal (S-shaped), as shown in Figure 3. The CoO single crystals exhibited only stages 1 and 2 of the threestage behavior typical of sigmoidal creep. Stage 1 consisted of an inflection in the creep curve shortly after loading, followed by a region in which the creep rate increased with increasing creep strain. The inflection, having a slope, $\dot{\varepsilon}_{1}$, resulted from the creep rate decreasing immediately after loading before it began to increase with increasing creep strain. Stage 2 is a region of continuously decreasing creep rate with increasing creep strain. The creep rate at the 
TABLE 1. TRANSVERSE DIMENS IONS AND STRA IN DISTRIBUTION ALONG SPECIMEN GAGE LENGTH AFTER CREEP

\begin{tabular}{|c|c|c|c|c|c|c|}
\hline $\begin{array}{l}\text { Specimen } \\
\text { Number }\end{array}$ & $\begin{array}{c}\text { Initia1 } \\
\text { Diameter, } \\
\text { inches }\end{array}$ & $\begin{array}{l}\text { Position of } \\
\text { Measurement }\end{array}$ & $\begin{array}{l}\text { Maximum } \\
\text { Diameter } \\
\text { (inches) }\end{array}$ & $\begin{array}{l}\text { Minimum } \\
\text { Diameter } \\
\text { (inches) }\end{array}$ & $\begin{array}{l}\text { Loca } 1 \\
\text { Strain, } \\
\left|\frac{A_{0}}{A_{f}}-1\right|\end{array}$ & $\begin{array}{c}\text { Total } \\
\text { Compressive } \\
\text { Strain, } \\
\left(\begin{array}{c}\frac{\Delta l}{l_{0}} \\
\hdashline o\end{array} \mid\right.\end{array}$ \\
\hline \multirow[t]{3}{*}{$1 C-2$} & 0.168 & End 1 & 0.170 & 0.166 & 0.024 & .084 \\
\hline & $"$ & Middle & 0.191 & 0.169 & 0.135 & \\
\hline & " & End 2 & 0.173 & 0.169 & 0.028 & \\
\hline
\end{tabular}

(a) The creep conditions were

$$
\text { IC-2: } 850 \mathrm{psi}, 1157^{\circ} \mathrm{C}, \mathrm{p}_{\mathrm{O}_{2}}=1.0 \mathrm{~atm} \text {. }
$$

(b) The minimum diameters after creep were used to calculate $A_{0}$ since the average of the minimum diameters agreed with the average initial diameter.

inflection in the creep curve dividing regions 1 and 2 is designated $\dot{\varepsilon}_{2}$. Stage 3, corresponding to steady state creep, with a constant creep rate, was not observed up to 0.085 creep strain. Presumably it would have been present at higher creep strains if the effects of barreling had been removed and the creep test continued ${ }^{(5)}$. The quantities $\epsilon_{2}, t_{2}$ and $t_{2}^{\prime}$ in Figure 3 have often been 
used in describing sigmoidal creep curves, and they are included in the summary of the creep results in Table 2. The terms $\varepsilon_{2}$ and $t_{2}$ are the strain and time of the inflection, respectively.

Sigmoidal creep curves have often been observed in non-metallic single crystals during creep, e.g., $\mathrm{Ge}^{(6-11)}, \mathrm{Si}^{(6,12,13)}, \operatorname{InSb}(14,15), \operatorname{LiF}(16,17)$, doped

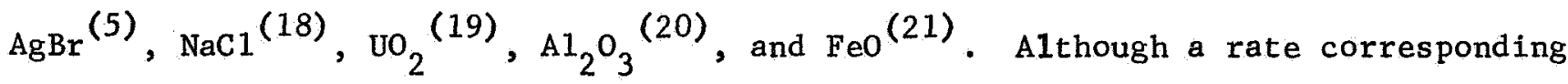
to $\dot{\varepsilon}_{1}$ has not been reported, this may be a matter of the sensitivity of the strain measuring device.

In the absence of a steady state creep rate, and because of the wide scatter and low values of $\dot{\varepsilon}_{1}$, only the creep rate $\dot{\varepsilon}_{2}$ was used to characterize the creep behavior of the CoO crystals. The creep specimens were machined from two as-received single crystal boules of $\mathrm{CoO}$, and specimens from both of these boules were used to determine the temperature, stress, and $\mathrm{p}_{\mathrm{O}_{2}}$ dependence of $\dot{\varepsilon}_{2}$. Considerable variations in the values of $\dot{\varepsilon}_{2}$ were observed between the two boules employed, but data from specimens taken from a given boule were selfconsistant. This difference in creep properties between the boules persisted over a range of temperature, stress, and $\mathrm{P}_{\mathrm{O}_{2}} \cdot$ By assuming that the difference between boules was not dependent on temperature, stress, or $\mathrm{P}_{\mathrm{O}_{2}}$, the variations in the plots of temperature, stress, and $\mathrm{p}_{\mathrm{O}_{2}}$ dependence of $\dot{\varepsilon}_{2}$ could be reduced considerably by multiplying the experimental values of $\dot{\varepsilon}_{2}$ from one of the boules by a factor of 3. The solid data points in Figures 4-6 are from one boule and have been multiplied by this factor. This treatment was necessary in order to allow a meaningful analysis of results.

An optical emission analysis was performed on each boule to determine whether the difference in creep properties between the boules was due to impurities. The levels of impurities in each boule were identical within the accuracy 
8

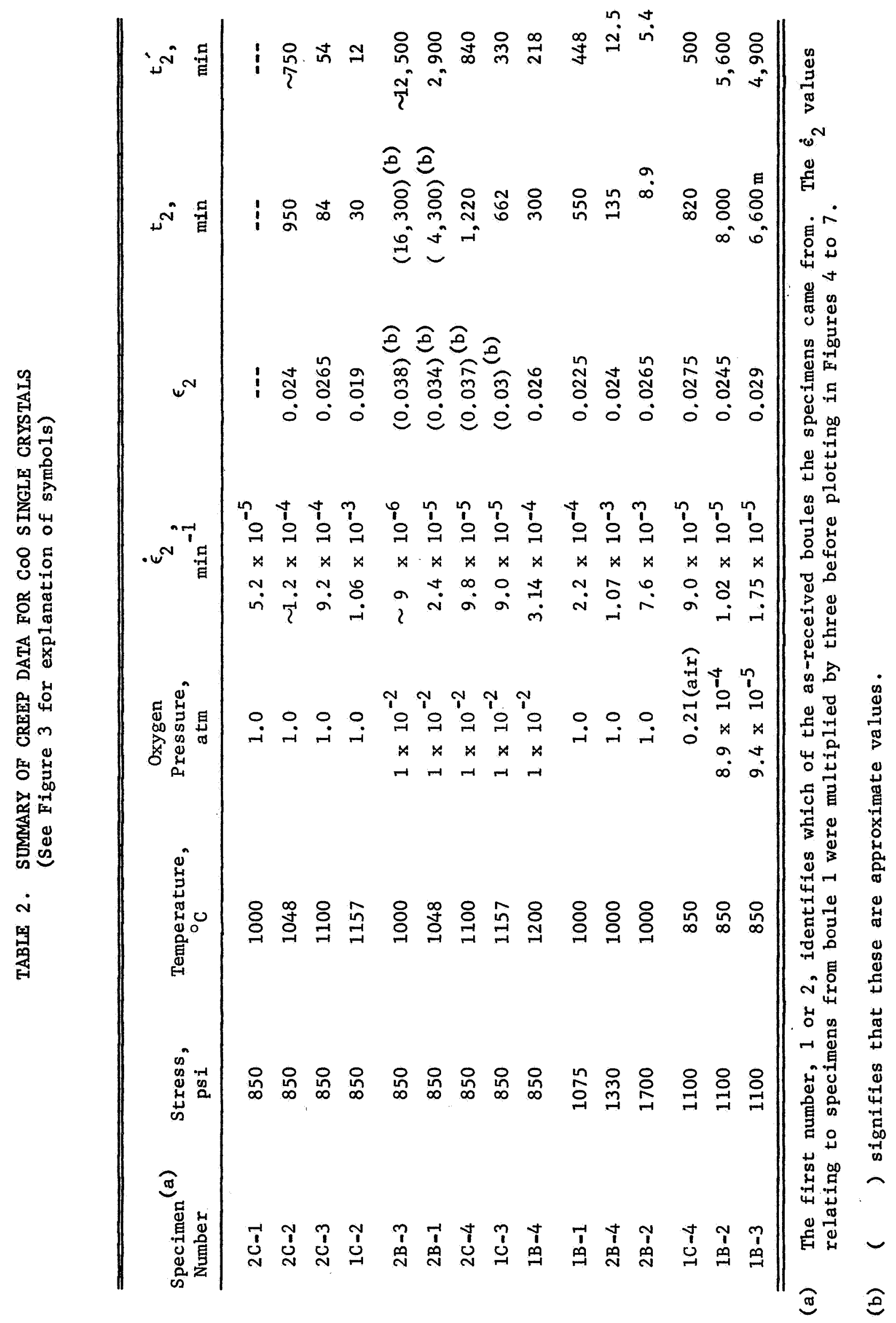


of the technique. The results of the analysis in weight percent were $\mathrm{Si}, 0.001-$ $0.002 ; \mathrm{Mn}, 0.02 ; \mathrm{Fe}, 0.05 ; \mathrm{Mg}, 0.01 ; \mathrm{Al}, 0.008 ; \mathrm{Cu}$, trace; $\mathrm{Ni}, 0.1, \mathrm{Ca}, 0.003$; other elements were sought but not found. Therefore any impurity effect must be attributed to a difference in concentration of impurities below the level of the sensitivity of this method of analysis. A difference in the grown-in dislocation substructure could also have been responsible for the difference in creep strength of the two boules, but such a variation could not be observed.

The temperature dependence of $\dot{\varepsilon}_{2}$ was measured at a constant stress of $850 \mathrm{psi}$ and under two partial pressures of oxygen, $\mathrm{p}_{\mathrm{O}_{2}}=1$ atm and $10^{-2}$ atm, and the results are shown in Figure 4. The slopes of the least mean squares lines give apparent activation energies of $Q_{c}=87.1 \pm 2.3 \mathrm{kcal} / \mathrm{mol}$ at $\mathrm{P}_{\mathrm{O}_{2}}=10^{-2} \mathrm{~atm}$. and $Q_{c}=99.8 \pm 7.7 \mathrm{kcal} / \mathrm{mol}$ at $\mathrm{p}_{\mathrm{O}_{2}}=1 \mathrm{~atm}$ *

The stress dependence of $\dot{\varepsilon}_{2}$ is shown in Figure 5 for $\mathrm{p}_{0_{2}}=1$ atm and a test temperature of $1000^{\circ} \mathrm{C}$. The results can be represented by a power law, $\dot{\epsilon}_{2} \propto \sigma^{n}$, where the least squares fit to the points gives $n=6.8 \pm 0.8$. This is larger than values reported for single crystals of other ionic compounds with the NaC1 crystal structure, e.g., $n=4.15$ in $\mathrm{Fe}_{1-\mathrm{x}} \mathrm{O}^{(21)}$ and $\mathrm{n}=5.6$ for $\mathrm{NaCl}$ using the replotted data of Ilschner and Reppich ${ }^{(18)}$. These in turn differ from the results for single crystals of covalently bonded materials with the diamond structure where $\mathrm{n}=3.3$ in $\mathrm{Ge}^{(22)}, \mathrm{n}=3.3$ in $\operatorname{InSb}{ }^{(15)}$ and $\mathrm{n}=3.0$ in $\mathrm{Si}^{(12)}$. However, the higher stress exponent for $\mathrm{CoO}$ is in accord with the tendency for ionic crystals to have larger exponents than the covalently bonded crystals. In

\footnotetext{
As noted above the solid data points (Figures 4-6) are from one boule and were obtained by multiplying $\dot{\varepsilon}_{2}$ values in Table 2 by a factor of three. If the actual uncorrected data are used the creep parameters determined from a least mean squares analysis give the following results: $Q_{c}=77.1 \pm 12 \mathrm{kcal} / \mathrm{mol}$ at $\mathrm{P}_{\mathrm{O}_{2}}=1 \mathrm{~atm} ; \mathrm{Q}_{\mathrm{c}}=60.0 \pm 6.5 \mathrm{kcal} / \mathrm{mol}$ at $\mathrm{P}_{\mathrm{O}_{2}}=0.01 \mathrm{~atm} ; \dot{\varepsilon}_{2} \propto \sigma 7.3 \pm 0.2 ;$

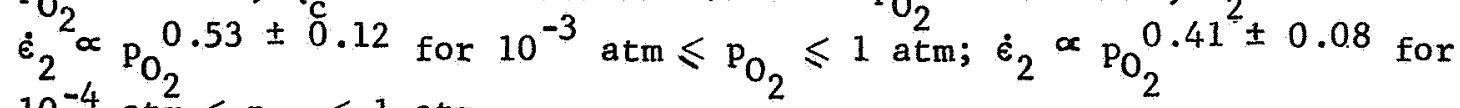
$10^{-4}$ atm $\leqslant \mathrm{P}_{\mathrm{O}_{2}} \leqslant 1$ atm.
} 
polycrystalline $\mathrm{Co}_{1-\mathrm{x}} \mathrm{O}$ scales tested in bending, strafford and Gartside ${ }^{(3)}$ observed that the steady-state creep rate was proportional to $\sigma^{2-3}$. The lower exponent here was probably due to grain boundary effects.

The $\mathrm{p}_{\mathrm{O}_{2}}$ dependence of $\dot{\varepsilon}_{2}$ is shown in Figure 6 as a power law relation, $\dot{\epsilon}_{2} \propto \mathrm{p}_{\mathrm{O}_{2}} 0.48 \pm 0.01$. From the phase diagram of $\mathrm{Co}_{1-\mathrm{x}} \mathrm{O}$ given by Fisher and Tannhauser ${ }^{(23)}$ the composition dependence of $\dot{\varepsilon}_{2}$ can be determined. Figure 7 shows that according to a power law relation, $\dot{\varepsilon}_{2} \propto x^{1.75}$. In accord with this study, Strafford and Gartside ${ }^{(3)}$ observed that the steady-state creep rate, $\dot{\varepsilon}_{s}$, of polycrystalline $\mathrm{CoO}$ scales increased with increasing $\mathrm{P}_{\mathrm{O}_{2}}$. However the creep rate was not very sensitive to oxygen pressure, being $\dot{\epsilon}_{\mathrm{s}} \propto \mathrm{p}_{\mathrm{O}_{2}} 0.14$ or $\dot{\epsilon}_{\mathrm{s}} \propto \mathrm{x}^{0.5}$. In contrast, $\dot{\varepsilon}_{2} \propto x$ for polycrystalline $\mathrm{Fe}_{1-\mathrm{x}} \mathrm{o}^{(21)}$ and similarly $\dot{\epsilon}_{\mathrm{s}} \propto \mathrm{x}$ for steady state bending creep of polycrystalline $\mathrm{UO}_{2+\mathrm{x}}$ (24). The exact dependence of the creep rate on composition will depend on the mechanism of creep. For example, if a diffusion controlled mechanism is operative, the composition dependence can be related to the concentration of the slowest moving point defect, and the oxygen partial pressure. Depending on this functional relation, it is possible to observe different dependencies of the creep rate on $\mathrm{P}_{\mathrm{O}_{2}}$ and $\mathrm{x}$.

The point at $\mathrm{p}_{\mathrm{O}_{2}}=10^{-4}$ atm in Figure 6 (and $\mathrm{x} \approx 8 \times 10^{-4}$ in Figure 7) is significantly above the lines representing $\dot{\varepsilon}_{2} \propto \mathrm{p}_{\mathrm{O}_{2}} 0.48$ and $\dot{\varepsilon}_{2} \propto \mathrm{x}^{1.75}$. This could be a real effect wherein the creep rate became independent of the oxygen pressure at low $\mathrm{p}_{\mathrm{O}_{2}}$. However, there was also a possibility that the specimen at $\mathrm{p}_{\mathrm{O}_{2}}=10^{-4}$ atm was not at the equilibrium composition before and during creep testing. To investigate this possibility, two specimens, approximately the same size as the creep specimens, were annealed at $1100^{\circ} \mathrm{C}$ for 66 hours (the time used to equilibrate all creep specimens) in $\mathrm{p}_{\mathrm{O}_{2}}=1$ atm and $\mathrm{p}_{\mathrm{O}_{2}}=10^{-4}$ atm. They were water quenched, and then metallographically polished on transverse cleaved 
sections. Figures 8 and 9 show the structures observed. Figure 8 reveals that after annealing in 1 atm $\mathrm{O}_{2}$, the $\mathrm{Co}_{3} \mathrm{O}_{4}$ particles are sma11 and uniformly distributed over the entire cross-section. * However, after annealing at $\mathrm{p}_{\mathrm{O}_{2}}=10^{-4}$ atm the structure was not uniform over the entire cross-section (see Figure 9). In the as-polished condition no precipitates or structure were observed, but after etching a gradient in the microstructure appeared, consisting of clusters of pits in the center of the specimen (Figure 9a) and a clear area at the outside surface (Figure 9b). Because the microstructure was not homogeneous after the quench, it is probable that the equilibrium composition was not attained during the pre-creep 66-hour anneal at $\mathrm{p}_{\mathrm{O}_{2}}=10^{-4}$ atm. The reason for this is clear from the phase diagram of Fisher and Tannhauser ${ }^{(23)}$. For $\mathrm{Co}_{1-\mathrm{x}} \mathrm{O}$ at $1100^{\circ} \mathrm{C}$ and $\mathrm{p}_{\mathrm{O}_{2}}=1$ atm, $\mathrm{x} \cong 0.008$, whereas at $\mathrm{p}_{\mathrm{O}_{2}}=10^{-4}$ atm, $\mathrm{x} \cong 0.0008$. Thus, there are ten times as many cobalt vacancies available for diffusion at $\mathrm{p}_{\mathrm{O}_{2}}=1$ atm than at $\mathrm{P}_{\mathrm{O}_{2}}=10^{-4} \mathrm{~atm}$. As the stoichiometric composition is approached, this makes the approach to equilibrium composition much slower at lower $\mathrm{p}_{\mathrm{O}_{2}}$. Furthermore, because the composition became more stoichiometric as $\mathrm{p}_{\mathrm{O}_{2}}$ decreased, 1 ess $\mathrm{Co}_{3} \mathrm{O}_{4}$ precipitated during cooling as shown in Figures 8 and 9 . The actual composition of the specimen at $\mathrm{p}_{\mathrm{O}_{2}}=10^{-4}$ atm was probably equivalent to a composition in equilibrium with a higher $\mathrm{P}_{\mathrm{O}_{2}}$. Therefore in Figures 6 and 7 the data points corresponding respectively to $\mathrm{p}_{\mathrm{O}_{2}}=10^{-4}$ atm and $\mathrm{x}=8 \times 10^{-4}$ would be shifted to the right.

\section{Deformation Mode}

The operative slip direction in crystals having the sodium chloride crystal structure is predominantly $<110>$, although $<100>$ has been reported in the Co/0 phase diagram (23), the material should be single phase above about $950^{\circ} \mathrm{C}$. 
$\mathrm{PbS}^{(25)}$ and $\mathrm{PbTe}{ }^{(26,27)}$. The primary slip planes are $\{110\}$, and $\{100\}$ while $\{111\}$ slip planes have been reported under certain conditions ${ }^{(28)}$.

The slip systems operating during creep in CoO could not be identified directly since no slip lines were visible after creep. However one specimen did not deform symmetrica11y but sheared by a relative sideways displacement of its end faces. The slip lines were readily visible in this specimen as shown in Figure 10. In Figure 10a the slip lines are straight and there are large offsets on the right and left sides of the specimen, indicating that screw dislocations exit through the (100) plane and the slip direction is parallel to this surface. In Figure $10 \mathrm{~b}$ the slip lines are wavy and there are no distinguishable offsets on the right and left sides of the specimen, indicating that edge dislocations exit from the (010) plane. Since the specimen axis is a<001> direction, and the photographs are parallel to $\{100\}$ planes, the slip system in Figure 10 is a $<110>\{110\}$ system.

The specimen orientation was indexed relative to the specimen shape after creep. The compression axis was parallel to [001], the minor axis of the elliptical cross-section was parallel to [100], and the major axis of the crosssection was parallel to [010]. The identification of the planes parallel to the photographs in Figure 10 are consistent with this. Thus the slip system in Figure 10 is the $[011](0 \overline{1} 1)$ system. If one now visualizes the simultaneous

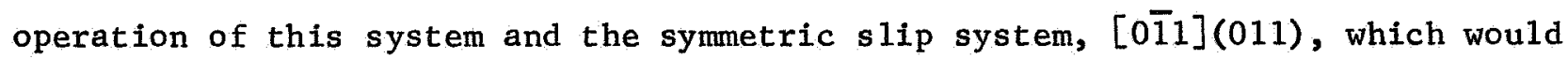
produce slip lines of the same form perpendicular to those in Figure 10, the observed shape change and barreling in the specimens which deformed "normally" becomes clear. 


\section{Creep Substructure}

The dislocation substructure developed during creep could not be observed in detail because of the local deformation introduced around particles of $\mathrm{Co}_{3} \mathrm{O}_{4}$ which precipitated during cooling (below $\sim 900^{\circ} \mathrm{C}$ ) from the creep temperature. Subsequent examination by etch pitting and transmission electron microscopy, as shown in Figure 11, verified that large numbers of dislocations were introduced by these particles, particularly around the larger particles ${ }^{(4)}$. Therefore the creep substructure was studied on mechanically polished $\{100\}$ surfaces by relying on decoration of sub-boundaries or groups of dislocations by the $\mathrm{Co}_{3} \mathrm{O}_{4}$ precipitates. This was not completely satisfactory, but it did reveal some details of the creep substructure. The as-received crystals rarely showed a decorated sub-boundary.

A specimen creep tested at a high stress, 1700 psi, formed subboundaries during creep as shown in Figure 12. The two plane trace analysis of Figure 12 indicates that the rows of particles represent planes paralle1 to (0īi). The sub-boundary plane associated with the faint rows of particles paralle1 to the specimen axis on the (010) surface in Figure 12 cannot be identified unequivocally since no particular set of precipitate rows can be associated with them on the (100) surface. However, they are consistent with (100) twist boundaries composed of screw dislocations from the two operative slip systems, (011)[011] and $(0 \overline{1} 1)[011]$. These would be paralle1 to the (100) view.

A regular array of sub-boundaries predominantly parallel to the traces of two perpendicular $\{110\}$ planes is shown in Figure 13. This specimen was creep tested at a lower stress, 930 psi. This $\{100\}$ surface is in the plane of the diameter having the largest dimensional increase during creep. Therefore the $\{110\}$ traces shown in Figure 13 are parallel to the traces of the active $\{110\}$ slip planes, (011) and (011). 
It was presumed that a straightforward relation between the substructure and slip could be obtained from an examination of the substructure within the specimen shown in Figure 10. However, no discernible substructural pattern was revealed by the precipitates as shown on longitudinal sections in Figure 14 .

From the general appearance of the decorated sub-boundaries after creep, most of the regular boundaries formed during creep are either parallel to (0ī1) or (011) planes. Also, the spacing between the decorated boundaries decreased with increasing stress as seen in Figures 12 and 13 . However, the conditions under which the boundaries formed are not clear. Of a series of specimens creep tested at $\mathrm{p}_{\mathrm{O}_{2}}=1 \mathrm{~atm}, 1000^{\circ} \mathrm{C}$ and different stresses from 850 to $1700 \mathrm{psi}$, on $1 \mathrm{y}$ the specimens tested at 850 and 1700 psi contained decorated sub-boundaries. Their absence after creep at 1075 and 1330 psi may be dependent to a greater extent on the decoration process than on the presence of sub-boundaries. If conditions during cooling from the creep temperature in some cases favored more homogeneous nucleation of the precipitate, the sub-boundary pattern would not be visible. Etch pitting did appear to bring out some sub-boundaries but the results were not definitive.

Transmission electron microscopy was performed on foils thinned from slabs cleaved parallel to (100) or (010) planes after creep. Numerous $\mathrm{CO}_{3} \mathrm{O}_{4}$ particles were observed both within the subgrains and within the sub-boundaries themselves. Individual dislocation loops were visible around smal1 particles, but the large particles had a general accumulation of dislocation debris surrounding them. An example of a particle of intermediate size is shown in Figure 11b. It is cubic in shape, with its faces parallel to the $\{100\}$ planes of the CoO crystal lattice.

Two types of sub-boundaries observed in creep tested CoO single crystals are shown in Figure 15. A sub-boundary in an area away from large particles is seen in Figure 15a. This foil plane was parallel to the (010) 
plane in the specimen shown in Figure 12. The boundary trace is parallel to the [100] direction in Figure 15 a just as the rows of precipitate are on the (010) view in Figure 12 .

The complication introduced by the particle-induced dislocations made the Burgers vector determination of the sub-boundaries difficult. The general line direction of many of the dislocations in the boundary in Figure 15a is parallel to $[100]$, corresponding to edge dislocations of $\underline{b}= \pm a / 2[0 \overline{1} 1]$ or $\underline{b}= \pm a / 2[011]$, which are the observed slip directions. This would contribute tilt character to the boundary. Figure $15 \mathrm{~b}$ shows a quite regular sub-boundary. It has the appearance of a twist boundary, but the relative tilt-twist character could not be measured except for a component of misorientation of $0.4^{\circ}$ around [100], which could be contributed by $\underline{b}^{\prime} s$ of $\pm a / 2[0 \overline{1} 1]$ and $a / 2[011]$, among others .

Hence boundaries having the appearance of predominantly tilt and twist character have been observed by TEM in CoO single crystals after creep. Although definite identification of the dislocations composing the boundaries could not be made, their appearance is consistent with the presence of slip dislocations having $\underline{b}=a / 2[0 \overline{1} 1]$ and $\underline{b}=a / 2[011]$.

\section{DISCUSSION}

An important point which must be emphasized in this discussion is the multiplying factor which was applied to the creep rates, $\dot{\varepsilon}_{2}$, from one of the boules. It is felt that this is justified since it is not unusual to have different levels of creep strength from two different crystals of a given binary compound. The creep properties can be sensitive to the presence of very small amounts of certain impurities. Also the grown-in dislocation substructure may 
be different in individually grown single crystals. The attempt to account for most of the variation by normalizing a very possible real difference in the relative creep strengths of the two boules is a logical approach. However the conclusions drawn must be viewed with this limitation in mind.

The activation energy for high temperature creep of binary compounds is usually diffusion controlled. Although this usually refers to the steady state creep rate in region 3 of Figure 3 , it also appears to apply to $\dot{\varepsilon}_{2}$. Diffusion rates for cobalt in $\mathrm{CoO}$ have been measured by Carter and Richardson ${ }^{(29)}$, while oxygen diffusivities have been determined by Thompson ${ }^{(30)}$, and more recently by Holt ${ }^{(31)}$ and by Chen and Jackson ${ }^{(32)}$. At 0.2 atm oxygen pressure Carter and Richardson (29) found the cobalt diffusion activation energy to be $34.5 \mathrm{kcal} / \mathrm{mol}$. Diffusivities increased as $\mathrm{p}_{\mathrm{O}_{2}}^{0.3}$ at $1150^{\circ} \mathrm{C}$ in the region $10^{-3}$ to 1 atm $\mathrm{P}_{\mathrm{O}_{2}}$. The diffusion coefficient for cobalt at $1150^{\circ} \mathrm{C}$ and 0.5 atm was $5 \times 10^{-9} \mathrm{~cm} / \mathrm{sec}$. These results may be compared with those of Chen and Jackson ${ }^{(32)}$ who found an activation energy for oxygen diffusion of $95 \mathrm{kcal} / \mathrm{mol}$ at 0.21 atm oxygen with a diffusivity of $2 \times 10^{-13} \mathrm{~cm}^{2} / \mathrm{sec}$ at $1175^{\circ} \mathrm{C}$. The partial pressure dependence of the oxygen diffusion rate in $\mathrm{CoO}$ has not been determined. Thompson ${ }^{(30)}$ reported an activation energy for oxygen diffusion of $36 \mathrm{kcal} / \mathrm{mol}$ at $0.13 \mathrm{~atm}$ oxygen and diffusion rates which give an extrapolated value of $10^{-10} \mathrm{~cm}^{2} / \mathrm{sec}$ at $1150^{\circ} \mathrm{C}$. However, it is believed that the more recent studies by Ho1t ${ }^{(31)}$, who used the proton activation technique, and by Chen and Jackson ${ }^{(32)}$, who used the isotopic exchange method, are more representative of bulk diffusion of oxygen in CoO. The results of these two investigators are in excellent agreement.

Diffusion controlled high temperature creep of binary compounds is usua1ly considered to be limited by the migration of the slower diffusing compound constituent. Using the more recent oxygen diffusion data it is seen that oxygen diffusion rates are some three to four orders of magnitude lower than 
the cobalt diffusivities at $1150^{\circ} \mathrm{C}$ and 0.2 atm oxygen pressure. Also, the values for $Q_{c}$ at $10^{-2}$ atm and 1 atm oxygen, 87.1 and $99.8 \mathrm{kcal} / \mathrm{mol}$, respectively, bracket the oxygen diffusion activation energy of $95 \mathrm{kcal} / \mathrm{mol}$ determined at $2 \times 10^{-1}$ atm and are much greater than the cobalt diffusion activation energy of $34.6 \mathrm{kcal} / \mathrm{mol}$. It can thus be concluded that high temperature creep of coo single crystals under these conditions is controlled by oxygen diffusion.

If high-temperature creep of $\mathrm{CoO}$ is controlled by oxygen diffusion, it remains to consider the mechanism for oxygen migration. Assuming that unassociated point defects predominate at the temperatures employed in this study the two possibilities are: (1) diffusion via vacancies in the oxygen sublattice or (2) interstitial diffusion of oxygen. It has been shown that $\dot{\epsilon}_{2} \propto \mathrm{p}_{0_{2}}{ }^{0.48}$ in the range $10^{-3}$ to 1 atm. This result suggests that oxygen interstitial diffusion is the rate controlling process, since the concentration of oxygen vacancies decreases with increasing oxygen partial pressure while the concentration of oxygen interstitials is an increasing function of $\mathrm{p}_{\mathrm{O}_{2}}$. If oxygen diffusion via vacancies in the anion sublattice were the predominant mechanism, creep rates should have decreased with increasing $\mathrm{p}_{\mathrm{O}_{2}}$. Furthermore, from the value of the exponent, 0.48 , it would appear that the oxygen diffuses as a neutral interstitial species. This conclusion follows from an analysis of the reactions by which oxygen may be assumed to enter $\mathrm{CoO}$ as an interstitial defect. Following the notation of Kroger and Vink ${ }^{(33)}$ the reaction for neutral oxygen interstitials may be written as:

$$
\begin{array}{lll}
1 / 2 & o_{2}(g) \rightarrow 0_{i}^{x}
\end{array}
$$

where $0_{i}^{x}$ is a neutral oxygen interstitial.

If oxygen interstitials act as acceptors of electrons, resulting in the formation of electron holes, the reactions for the introduction of singly ionized and 
doubly ionized interstitials may be written as:

$$
1 / 2 o_{2}(g) \rightarrow o_{i}^{\prime}+h,
$$

and

$$
1 / 2 \mathrm{O}_{2}(g) \rightarrow \mathrm{O}_{i}^{\prime \prime}+2 \mathrm{~h},
$$

where the primes on the oxygen interstitials represent negative charge and $h$ is an electron hole.

In $\mathrm{CoO}$ the predominant defects are cobalt vacancies ${ }^{(23)}$. At high oxygen pressures the neutrality condition is $\left[\mathrm{e}^{+}\right]=\left[\mathrm{V}_{\mathrm{Co}}^{\prime}\right]$ where $\left[\mathrm{e}^{+}\right]$and $\left[\mathrm{V}_{\mathrm{Co}}^{\prime}\right]$ are the concentrations of electron holes and singly ionized cobalt vacancies, respectively. At low oxygen pressures the neutrality condition is $\left[\mathrm{e}^{+}\right]=2\left[\mathrm{~V}_{\mathrm{Co}}^{\prime \prime}\right]$ where $\left[\mathrm{V}_{\mathrm{Co}}^{\prime \prime}\right]$ is the concentration of doubly ionized cobalt vacancies. The pressure dependence of the different concentrations of oxygen interstitials is as follows:

$$
\left[0_{i}^{x_{i}}\right] \propto \mathrm{p}_{0_{2}}^{1 / 2}
$$

independent of neutrality condition,

$$
\left[0_{i}^{\prime}\right] \propto \mathrm{p}_{0_{2}}^{1 / 4} ; \text { and }\left[0_{i}^{\prime \prime}\right]=\text { constant }
$$

for $\left[\mathrm{e}^{+}\right]=\left[\mathrm{V}_{\mathrm{Co}}^{\prime}\right]$,

$$
\left[0_{i}^{\prime}\right] \propto \mathrm{p}_{0_{2}}^{1 / 3} ; \text { and }\left[\mathrm{O}_{i}^{\prime \prime}\right] \propto \mathrm{p}_{0_{2}}{ }^{1 / 6}
$$

for $\left[e^{+}\right]=2\left[\mathrm{v}_{\mathrm{Co}}^{\prime}\right]$,

where $\left[\theta_{i}^{\mathrm{X}}\right],\left[0_{i}^{\prime}\right]$, and $\left[0_{i}^{\prime \prime}\right]$ are concentrations of neutral, singly ionized, and doubly ionized oxygen interstitials respectively.

Examination of the above equations shows that a pressure dependence of oxygen interstitials close to $\mathrm{p}_{\mathrm{O}_{2}}{ }^{0.48}$ is possible only if neutral oxygen interstitials control the creep. 
While the results of this study are the first to indicate the existence of oxygen interstitials in $\mathrm{CoO}$, investigations of oxygen diffusion in a number of other oxide systems have pointed to similar conclusions. For example, oxygen diffusion has been found to increase with increasing oxygen pressure in $\mathrm{NiO}^{(34)}, \mathrm{Cu}_{2} \mathrm{O}^{(35)}, \mathrm{ZnO}^{(36)}$, and most recently $\mathrm{MgO}^{(37)}$. The possibility that oxygen diffuses as an interstitial defect in oxides is often dismissed on the basis of size considerations. This argument is valid for interstitial migration of oxygen as $0^{\prime \prime}$ which has an ionic radius of $1.32 \AA$. However neutra1 oxygen has a radius of $0.60 \AA$ and may be expected to migrate with relative ease through $\mathrm{CoO}$.

It is also quite possible that oxygen migrates via complex point defects ${ }^{(38)}$. These associated defects might involve either oxygen interstitials or vacancies. Under the assumption that the predominant point defects are unassociated singly ionized cobalt vacancies at the creep temperatures (for $10^{-3}$ atm $\left.<\mathrm{P}_{\mathrm{O}_{2}}<1 \mathrm{~atm}\right)$, the most tenable associated defects whose concentration varies as $\mathrm{P}_{\mathrm{O}_{2}}{ }^{1 / 2}$ are $\left(0_{i}^{\prime} \mathrm{V}_{\mathrm{Co}}^{\prime}\right)^{\prime \prime}$ and $\left(2 \mathrm{~V}_{\mathrm{Co}}^{\prime} \mathrm{V}_{\mathrm{O}}^{\cdots}\right)^{\mathrm{x}}$. Here the terms $\mathrm{V}_{\mathrm{Co}}$ and $\mathrm{V}_{0}$ are cobalt and oxygen lattice vacancies and the dots represent positive charge. The associated defect $\left(0_{i}^{\prime} V_{M}^{\prime}\right)$ " was first suggested for $\mathrm{NiO}$ by Hoch ${ }^{(38)}$. However, the simpler unassociated neutral oxygen interstitial is consistent with the observed $\mathrm{p}_{0}$ dependence of the creep rate and there is no reason to discount this simpler defect at present.

The probability that $\dot{\varepsilon}_{2}$ is controlled by the migration of one of the compound constituents is consistent with other results in ionic binary compounds where S-shaped creep curves have been observed. This is in contrast to materials with a diamond crystal structure in which the rate controlling mechanism for $\dot{\varepsilon}_{2}$ is the glide of dislocations through the crystal lattice. Table 3 summarizes the activation energies for $\dot{\epsilon}_{2}$, diffusion, and dislocation movement for materials in 


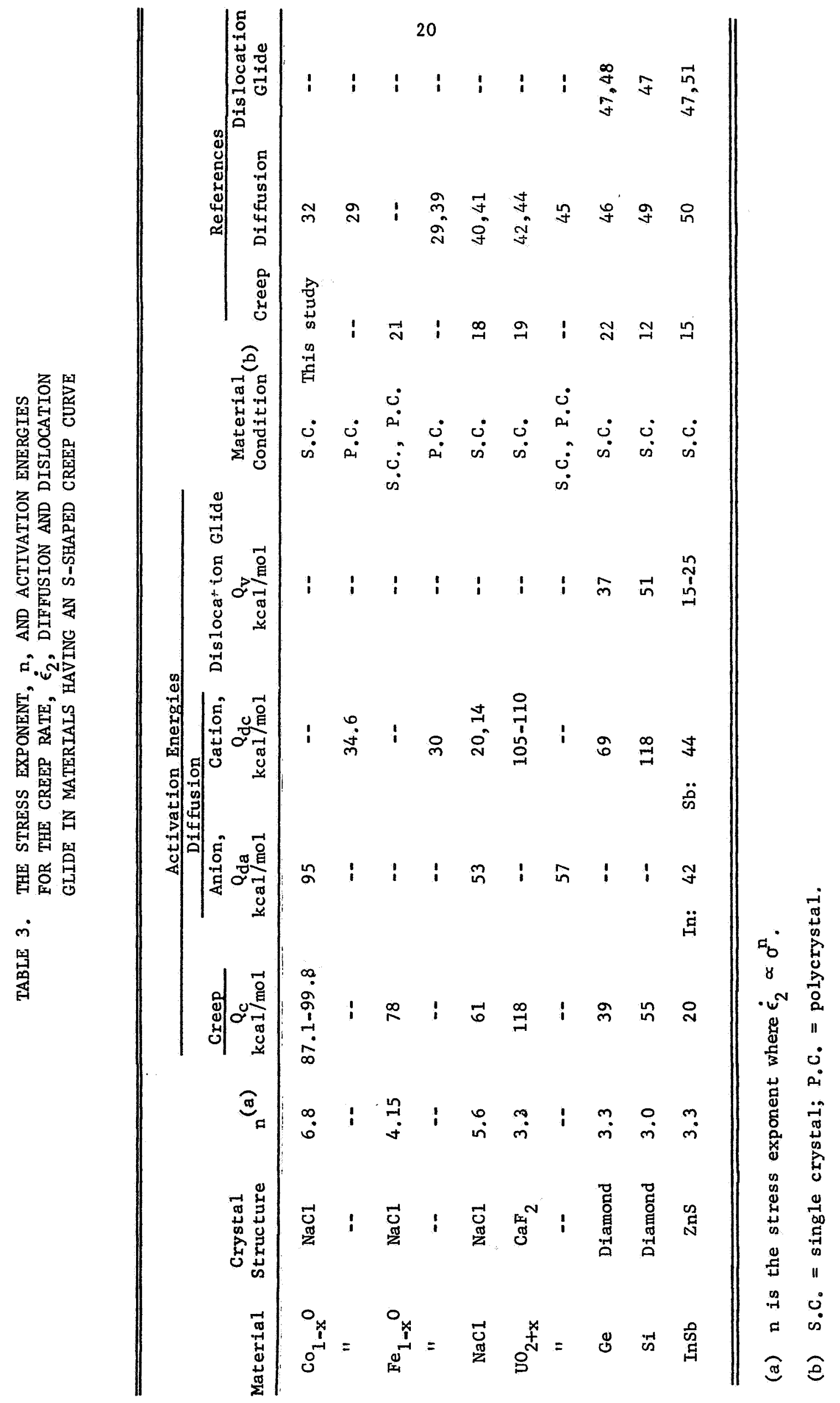


which an S-shaped creep curve has been observed. In $\mathrm{CoO}, \mathrm{NaCl}$, and $\mathrm{UO}_{2}$, the creep activation energies are very close to the activation energies for diffusion of one of the constituent species. In $\mathrm{FeO}$, the activation, energy for oxygen diffusion is not known and it is possible that $Q_{c}$ in FeO relates to oxygen diffusion. However, in the materials having the diamond structure (Ge, $S i$, and InSb), $Q_{c}$ is closer to the activation energy for dislocation glide than the activation energy for diffusion, $Q_{d}$.

The value of $Q_{v}$, the activation energy for dislocation glide, is not known for Coo. However for the covalent materials, $Q_{v} \approx 1 / 2 Q_{d}$. In ionic crystals, with less directional bonding, it would be expected that $Q_{v}$ would be even lower relative to $Q_{d}$. Therefore the observation that $Q_{c} \approx Q_{d}$ for oxygen in CoO strongly suggests that $\dot{\varepsilon}_{2}$ is controlled by diffusion rather than by dislocation gliding.

The model for creep in the covalently bonded materials is based on dislocation dynamics $(12,15,52)$. This model predicts $s-s h a p e d$ creep curves in crystals having a low initial mobile dislocation density. Simply, in region 1 of Figure 3 the number of mobile dislocations is increasing continuously with increasing strain, causing the creep rate to accelerate. However, in region 2 the dislocation density becomes sufficiently large that dislocation interactions cause the dislocation velocity to decrease resulting in a lower creep rate with increasing creep strain.

This model can also be applied qualitatively to creep in the CoO single crysta1s. Initially the mobile dislocation density may be quite low due to pinning by a high density of jogs or because of a low total dislocation density from annealing 66 hours in situ before testing. The dislocation dynamics model then explains the shape of the creep curve. In Haasen's model $(12,15)$ and also the model of Webster ${ }^{(53)}$, the temperature dependence of $\dot{\varepsilon}_{2}$ is associated primarily with the temperature dependence for dislocation glide. However in CoO this must be associated with an oxygen diffusion related process. 
Two possible creep mechanisms consistent with a dislocation dynamics approach are the glide of jogged screws $(54,55)$ and the glide of charged dislocations $(56,57)$. The glide of charged dislocations, dragging along an atmosphere of charged defects to maintain electrical neutrality, is not compatible with the diffusion of neutral oxygen interstitials since it would be the motion of the charged point defects in the charge cloud surrounding the moving dislocation which would control the dislocation glide.

Since in $\mathrm{CoO}$, cobalt vacancies are the predominant defects, a gliding dislocation would tend to sweep up mostly cobalt vacancies. The gliding dislocations would have predominantly oxygen ions at their jogs giving the dislocations a net negative charge. Sweeping of oxygen interstitials would cause the same result. The neutralizing charge cloud must then be composed of positively charged defects, and even the associated defect $\left(\mathrm{O}_{i}^{\prime} \mathrm{V}_{\mathrm{Co}}^{\prime}\right)$ " is not pertinent to this model.

The motion of jogged screws requires the diffusion of both a cobalt and an oxygen ion to complete a unit forward movement of the jog. In this case diffusion of the slower moving ion, oxygen, would be expected to be rate controlling. Also, this would be expected whether oxygen diffused as a simple or a complex defect or was either charged or uncharged. Therefore, it is suggested that a feasible rate controlling process for the inflection creep rate, $\dot{\varepsilon}_{2}$, is the oxygen diffusion limited glide of jogged screw dislocations. The reason for the large stress dependence is not clear at present. It may be caused by a stress dependence of the mobile dislocation density or possibly even the jog density. This discussion, of course, is pertinent only to the inflection creep rate, $\dot{\varepsilon}_{2}$. If steady-state creep had been reached in the present investigation, it is very possible that here another controlling mechanism, e.g., climb, could be operative. 


\section{Substructure}

The sub-boundaries decorated by the $\mathrm{Co}_{3} \mathrm{O}_{4}$ particles (Figures 12 and 13) may be either tilt boundaries created by climb of edge dislocations out of the (0ī1) and (011) glide planes, or glide dislocations lying in the glide planes. However, if the glide planes were so well defined by a high density of glide dislocations that they were preferentially decorated by the $\mathrm{Co}_{3} \mathrm{O}_{4}$ precipitate, it would be expected that large slip offsets would be visible on the surface with a spacing between them comparable to the spacing between the decorated boundaries. This has been observed in high temperature creep of molybdenum single crysta1s. (58) However no such slip bands were observed by optical microscopy (except in the one atypical case shown in Figure 10). Hence the decorated boundaries are probably sub-boundaries formed during creep, consistent with those observed by transmission electron microscopy in Figure 15. They were probably formed after the inflection of the creep curve, at larger creep strains where steady state creep was approached. The possibility of (100) twist boundaries, too, is entirely consistent with the formation of regular sub-boundaries where only two slip systems are operative ${ }^{(58)}$.

The absence of sub-boundaries in the specimen which deformed by slip on predominantly one slip system (Figures 10 and 14), may indicate that without the presence of a second set of dislocations having a different Burgers vector there are not sufficiently strong barriers to initiate the tilt wall formation or to pin them, once they have formed ${ }^{(58)}$. 


\section{Relevance of Creep Results to Oxidation Behavior}

The work on this program of Kofstad, Hed, and Billman has shown that CoO scales form during oxidation of $\mathrm{Co}$ and $\mathrm{Co}-\mathrm{Cr}$ alloys. The conditions they studied, where CoO layers formed, are:

$$
\begin{aligned}
& \text { pure Co: } 900-1300^{\circ} \mathrm{C}, \quad \mathrm{P}_{\mathrm{O}_{2}}=0.1-760 \text { torr } \\
& \text { Co-Cr, where } \mathrm{Cr}<10 \%: 900-1300^{\circ} \mathrm{C}, \quad \mathrm{P}_{\mathrm{O}_{2}}=0.1-760 \text { torr } \\
& \text { Co-25\% Cr: } 900-1300^{\circ} \mathrm{C}, \quad \mathrm{P}_{\mathrm{O}_{2}} \approx 100-760 \text { torr. }
\end{aligned}
$$

It is of interest to examine how CoO scales may creep in situ (i.e., during oxidation) and how the plasticity (or lack of plasticity) can influence scale morphology, adherence, and the general oxidation behavior. For purposes of discussion only the more simple case of oxidized pure Co will be considered. An example of such a scale is shown in Figure 16a. Here the pure Co specimen was oxidized for 6 hours at $1100^{\circ} \mathrm{C}$ in an atmosphere of pure oxygen. The CoO scale $(0.24 \mathrm{~mm}$ thick) is seen to have numerous pores, which are more concentrated near the metal/oxide interface. Although the scale appears to have separated from the metal*, it is probable that it was adherent at the oxidizing temperature. In this system the metal/oxide interface remains nearly fixed and the oxide grows by cation diffusion through the $\mathrm{CoO}$ and subsequent reaction with oxygen at the oxide surface. Since the molar volume of the coO formed is greater than the molar volume of the Co from which the oxide formed $(\phi$, the PillingBedworth ratio, is 1.8 ) compressive stresses probably are present in the scale at temperature. The magnitude and distribution of the stresses depend on: the degree of adherence of the scale to the metal (nature of the oxide/metal interface), the available plasticity of the scale (by which stress may be relieved by 
creep) and the number and distribution of pores (which are potential stress concentrators).

It was found that the inflection creep rate, $\dot{\varepsilon}_{2}$, of CoO single crystals was related to composition, $x$ in $\mathrm{Co}_{1-\mathrm{x}} \mathrm{O}$, and stress, $\sigma$, by the proportionality

$$
\dot{\epsilon}_{2} \propto \mathrm{x}^{1.75} \sigma^{6.8} \text {, at constant temperature. }
$$

Two hypothetical and highly simplified situations (Figure $16 \mathrm{~b}$ and $\mathrm{c}$ ) represent the influence of composition and stress in an oxide scale on the predicted scale creep rate. The conditions considered are: $\mathrm{T}=1100^{\circ} \mathrm{C}$ and $\mathrm{P}_{\mathrm{O}_{2}}=1$ atm, since these correspond to the conditions under which the scale in Figure 16a was formed and also to conditions under which CoO single crystals were creep tested. The actual stress levels chosen may not be representative of stresses in the scales at temperature. However they represent stresses where creep data are available, thus simplifying the calculation of relative creep rates. Thus the diagrams in Figure $16 \mathrm{~b}$ and $\mathrm{c}$ are probably reasonably correct in relative terms, but not necessarily accurate on an absolute basis. In plotting Figure $16 \mathrm{~b}$ and $\mathrm{c}$ the following assumptions were made:

\section{Figure 16b}

(a) The stress was constant (850 psi) across the whole scale thickness. No relaxation occurred by creep of the Co substrate.

(b) The value of $x$ at the surface was $10^{-2}$, which is approximately the equilibrium value at $1100^{\circ} \mathrm{C}$ and $\mathrm{P}_{0_{2}}=1$ atm ${ }^{(23)}$.

(c) The value of $x$ at the metal/oxide interface was arbitrarily taken to be $10^{-4}$. A decrease in $x$ from the scale surface to the metal is reasonable. Figure 16a (and other micrographs not shown) shows white particles of $\mathrm{Co}_{3} \mathrm{O}_{4}$ which 
precipitated after cooling below $\sim 900^{\circ} \mathrm{C}$. These are more pronounced near the oxide surface and are not visible at al1 near the metal/oxide interface. This gradation in $\mathrm{Co}_{3} \mathrm{O}_{4}$ particle density indicates that during oxidation $\mathrm{x}$ was higher at the oxide surface.

(d) A straight line was drawn for the composition-distance profile, which assumes that $\log x \propto c t$ where $t=\operatorname{scale}$ thickness .

(e) The possible influence of porosity was ignored.

Figure 16c

(a) The stress was highest at the oxide/metal interface (850 psi) and decreased linearly to half this value (425 psi) at the oxide surface. No relaxation occurred by creep of the Co substrate.

(b) The gradient in $\mathrm{x}$ was the same as that in Figure $16 \mathrm{~b}$.

(c) The possible influence of porosity was ignored.

If the above situations were to exist at a point in time during oxidation, then at that time it is seen that: (1) in Figure $16 \mathrm{~b}$, the coo near the surface would creep $\sim 2 \times 10^{3}$ times as fast as the oxide adjacent to the co substrate, and (2) in Figure 16c, the CoO near the surface would creep 20 times as fast as the oxide adjacent to the Co substrate. These observations of course must be regarded only as hypothetical, since:

(a) The true stress distribution at any point in time is not really known. However, the compressive stresses in the CoO scale would be expected to be largest immediately adjacent to the oxide/metal interface where the scale adheres to the metal substrate. During oxidation of Co, the oxide grows at the 
oxide/gas surface where the volume difference between the metal and oxide can be accommodated largely by growth normal to the oxide scale. Therefore it is expected that Figure 16c is more representative of the actual situation, since the stress is probably a maximum at or near the metal/oxide interface and decreases (possibly even to zero) at the oxide surface.

(b) The stress distribution probably changes with time, i.e., as creep occurs stresses are relaxed and the formation and growth of voids influences the stress distribution.

(c) The true composition-distance ( $x$ vs. thickness) profile is not known.

(d) The calculations were made using Equation (7), which represents creep results for single crystals. Polycrystalline creep data (which are presently being obtained) would probably provide more accurate results, since the CoO scales are polycrysta11ine.

In light of the above discussion it is useful to consider the gradation in porosity shown in Figure 16a. It can be concluded that the oxide is inherently more plastic near the surface than at the $\mathrm{Co} / \mathrm{CoO}$ interface, as a result of the composition variation. Also the stresses are more relaxed at the surface since creep is easier. These factors would favor fracture of the scale at or near the metal/oxide interface. This is consistent with the observation of a higher void density near the Co/CoO interface. Microcracks could have formed here initially, and subsequent vacancy condensation could account for their rounded appearance in Figure 16a. 
It is obvious that a rigorous and comprehensive description of the in situ creep behavior of CoO scales during oxidation of Co will be very complicated. Before this can be realized it will be necessary to have details of: (1) the magnitude and distribution of stress in scales, and how these vary with time, scale thickness, and temperature, (2) an accurate composition-distance profile ( $x$ vs, thickness), and how this varies with time and temperature, (3) how the scale adherence is influenced by temperature, and (4) a knowledge of how creep in the Co substrate can assist in relaxing stresses in the oxide scale, e.g., slow tensile creep rates in the Co substrate would aid in relieving compressive stresses in the oxide.

The above discussion, of course, pertains only to oxide scale creep during isothermal oxidation. In many applications oxidized metals are thermally cycled. During the cycling, stress magnitudes and distributions change as a result of differences in thermal expansion between the metal and oxide. Furthermore, metals are often subjected to dynamic oxidation situations in a fast moving gas stream. Here frictional forces and impact by foreign particles can alter the stress state in the scale. These complications ultimately must be taken into account before there can be a comprehensive picture of how oxide creep and plasticity can influence the oxidation and scaling of metals in specific applied situations.

\section{CONCLUSIONS}

1. Compression creep curves of $\mathrm{CoO}$ single crystals with $\langle 100\rangle$ compression axes have a sigmoidal shape.

2. The activation energy for the creep rate at the inflection of the creep curve, $\dot{\varepsilon}_{2}$, was $87.1 \pm 2.4 \mathrm{kcal} / \mathrm{mol}$ at $\mathrm{p}_{\mathrm{O}_{2}}=0.1$ atm and $99.8 \pm 7.7 \mathrm{kcal} / \mathrm{mol}$ 
at $\mathrm{p}_{\mathrm{O}_{2}}=1.0 \mathrm{~atm}$. These values are in good agreement with the activation energy for self diffusion of oxygen in $\mathrm{CoO}, 95 \mathrm{kcal} / \mathrm{mol}$ at $\mathrm{P}_{\mathrm{O}_{2}}=0.2$ atm.

3. The stress dependence of $\dot{\varepsilon}_{2}$ was $\dot{\varepsilon}_{2} \propto \sigma^{6.8 \pm 0.3}$.

4. The oxygen pressure dependence of $\dot{\varepsilon}_{2}$ was $\dot{\varepsilon}_{2} \propto \mathrm{p}_{0_{2}}{ }^{0.48 \pm 0.01}$.

5. The composition dependence of $\dot{\epsilon}_{2}$ in terms of $\mathrm{Co}_{1-\mathrm{x}} \mathrm{O}$ was $\dot{\epsilon}_{2} \propto \mathrm{x}^{1.75}$.

6. The slip systems were of the type $\langle 011>\{110\}$.

7. Sub-boundaries formed during creep were observed by decoration with $\mathrm{Co}_{3} \mathrm{O}_{4}$ precipitates. These boundaries were parallel to $(011)\{011\}$ and may be either tilt or glide boundaries.

8. It is probable that oxygen diffusion controls the creep of CoO single crystals over the range of conditions investigated in this study. The predominant creep mechanism may be the glide of jogged screw dislocations, their motion being controlled by diffusion of neutral oxygen interstitials .

9. A quantitative description of $\mathrm{CoO}$ scale creep during oxidation of pure Co is very difficult. It can be said, however, that the scale at the surface will be more plastic than the $\mathrm{CoO}$ near the metal/oxide interface.

\section{ACKNOWLEDGMENTS}

The able technical assistance of M. R. Cantin, J. R. Bibler, and R. D. Tenaglia is gratefully acknowledged. The authors are indebted to A. Z. Hed and F. R. Billman for valuable discussions. 


\section{REFERENCES}

(1) I. A. Menzies and K. N. Strafford, J. Mat. Sci., 2, 358 (1967).

(2) J. D. Mackenzie and C. E. Birchena11, Corrosion, 13, 783 (1957).

(3) K. N. Strafford and H. Gartside, Nature, 220, [5163], 158 (1968).

(4) M. R. Cantin, A. H. Clauer, M. S. Seltzer, and B. A. Wilcox, J. Am. Ceram. Soc., 52, 112 (1969).

(5) R. W. Christy, Acta Met., 2, 284 (1954).

(6) C. J. Gallagher, Phys. Rev., 88, 721 (1952).

(7) J. R. Patel and B. H. Alexander, Acta Met., 4, 385 (1956).

(8) H. G. Van Bueren, Physica, 24, 831 (1958).

(9) P. Penning and G. de Wind, Physica, 25, 765 (1959).

(10) D. Dew Hughes, IBM Journa1, 45, 279 (1961).

(11) M. M. Shea, L. E. Hendrickson, and L. A. Heldt, J. Appl. Physics, 37, 4572 (1966).

(12) B. Reppich, P. Haasen, and B. Ilschner, Acta Met., 12, 1283 (1964).

(13) T. Taylor, Ph.D. dissertation, Stanford University, 1968.

(14) J.W. Allen, Phil. Mag., 2, 1475 (1957).

(15) E. Peissker, P. Haasen, and H. Alexander, Phil. Mag., 7, 1279 (1961).

(16) W. G. Johnston, J. App1. Phys., 33, 2716 (1962).

(17) W. A. Coghlan, Ph.D. dissertation, Stanford University, 1969.

(18) B. Ilschner and B. Reppich, Phys. Stat. Sol., 3, 2093 (1963).

(19) W. M. Armstrong, A. R. Causey, and W. R. Sturrock, J. Nuc1. Mater., 19, 42 (1966).

(20) J. B. Wachtman and L. H. Maxwe11, J. Am. Cer. Soc., 40, 377 (1957).

(21) B. Reppich, Phys. Stat. Sol., 20, 69 (1967).

(22) J. Hewing, Diplomarbeit Göttingen, from P. Haasen, NPL Symp., The Relation Between Structure and Mechanical Properties of Metals, HMSO, London (1963). 
(23) B. Fisher and D. S. Tannhauser, J. Electrochem. Soc., 111, 1194 (1964).

(24) W. M. Armstrong and W. R. Irvine, J. of Nuc1. Mater., 9, 121 (1963).

(25) M. J. Buerger, Amer. Min., 15, 21, 35 (1930).

(26) J. J. Gilman, Acta Met., I, 608 (1959).

(27) W. A. Rachinger, Acta Met,, 4, 647 (1956).

(28) J. P. Hirth and J. Lothe, Theory of Dislocations, McGraw-Hi11 Book Co., New York, 1968.

(29) R. E. Carter and F. D. Richardson, Trans. AIME, 200, 1244 (1954).

(30) B. A. Thompson, Ph.D. dissertation, Rensselaer Polytechnic Institute, 1962, University Microfilms, Ann Arbor, Michigan, 1963.

(31) J. B. Holt, Proc. Brit. Ceram. Soc., [9], 157 (1967).

(32) W. K. Chen and R. S. Jackson, "Oxygen Self Diffusion in Doped and Undoped Cobaltous Oxide", Metallurgy Div., Argonne National Lab., Argonne, I11., September, 1968.

(33) F. A. Kröger and H. J. Vink, Solid State Physics, $\underline{3}, 307$ (1956).

(34) M. O'Keeffe and W. J. Moore, J. Phys. Chem., 65, 1438 (1961).

(35) W. J. Moore, Y. Ebisuzaki, and J. A. Sluss, J. Phys. Chem., 62, 1438 (1958).

(36) W. J. Moore and E. L. Williams, Disc. Faraday Soc., 28, 86 (1959).

(37) L. H. Rovner, Ph.D. dissertation, Cornel1 University, 1966, University Microfilms, Ann Arbor, Michigan.

(38) M. Hoch and R. Szwarc, Tech. Report AFML-TR-67-331, November, 1967, University of Cincinnati.

(39) L. Himme1, R. F. Meh1, and G. E. Birchena11, Trans. AIME, 197, 827 (1953).

(40) D. Mapother, H. W. Crooks, and R. J. Meurer, J. Chem. Phys ., 18, 1231 (1950).

(41) J. F. Laurent and J. Benard, J. Phys. Chem. Solids, 3, 7 (1957).

(42) C. B. Alcock, R. J. Hawkins, A.W.D. Hills, and P. McNamara, Thermodynamics (IAEA) Vienna, 1966, SM 66/36.

(43) P. McNamara, Thesis, London (1963).

(44) R. J. Hawkins and C. B. Alcock, J. Nuc1. Mat., 26, 112 (1968).

(45) J. Belle, J. Nuc1. Mat., 30, 3 (1969). 
(46) H. Letaw, W. M. Portnoy, and L. M. Slykin, Phys, Rev., 102, 636 (1956).

(47) A. R. Chaudhuri, J. R. Pate1, and L. G. Rubin, J. App1. Phys ., 33, 2736 (1962).

(48) S. Schäfer, Phys. Stat. So1., 19, 297 (1967).

(49) J. M. Fairfield and B. J. Masters, J. App1. Phys., 38, 3148 (1967).

(50) F. H. Eisen and C. E. Birchenal1, Acta Met., 5, 265 (1957).

(51) H. Steinhardt, Diploma Thesis, Göttingen (1968), re: ref (326).

(52) P. Haasen, Dislocation Dynamics, Ed. by A. R. Rosenfield, G. T. Hahn,

A. L. Bement, and R. I. Jaffee, McGraw Hill Book Co., New York (1968), p. 701 .

(53) G. A. Webster, Phil. Mag., 14, 775 (1966).

(54) N. F. Mott, Creep and Fracture of Metals at Elevated Temperatures, London, HMSO (1956) p. 21.

(55) C. R. Barrett and W. D. Nix, Acta Met., 13, 1247 (1965).

(56) F. Bassani and R. Thomson, Phys. Rev., 102, 1264 (1956).

(57) J. D. Eshelby, C.W.A. Newey, P. L. Pratt, and A. B. Lidiard, Phil . Mag., $\underline{3}, 75$ (1958).

(58) A, H. Clauer, B. A. Wilcox, and J. P. Hirth, to be published in Acta Met. 


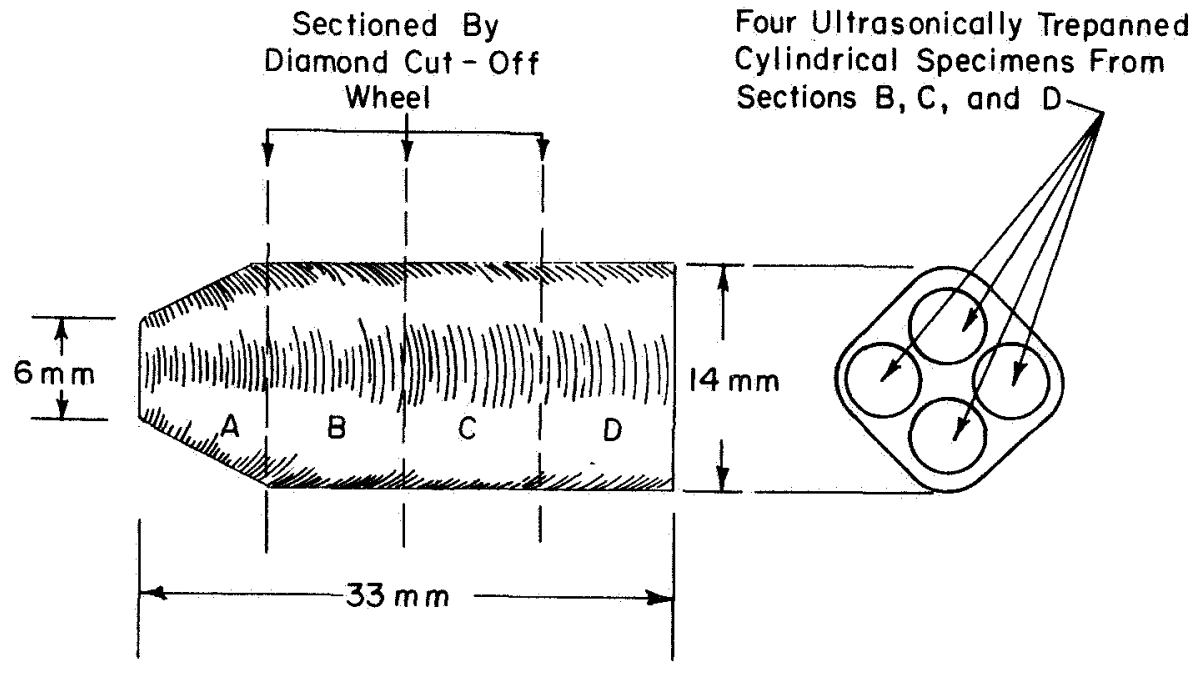

Final Cylindrical

Compression Creep

Specimen

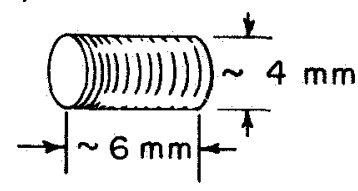

Figure 1. Procedure by Which the Creep Specimens were Machined from As-Received Single Crystal Boules 

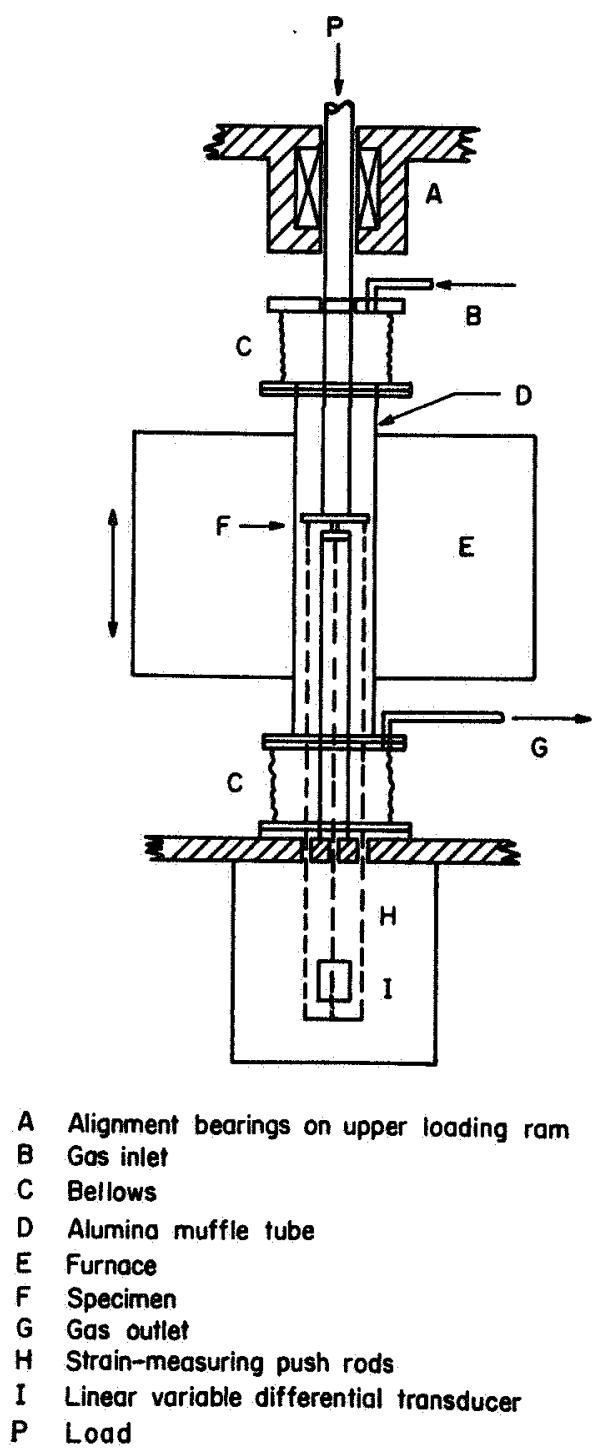

Figure 2. Compression Creep Furnace for Creep Testing in Controlled Atmospheres 


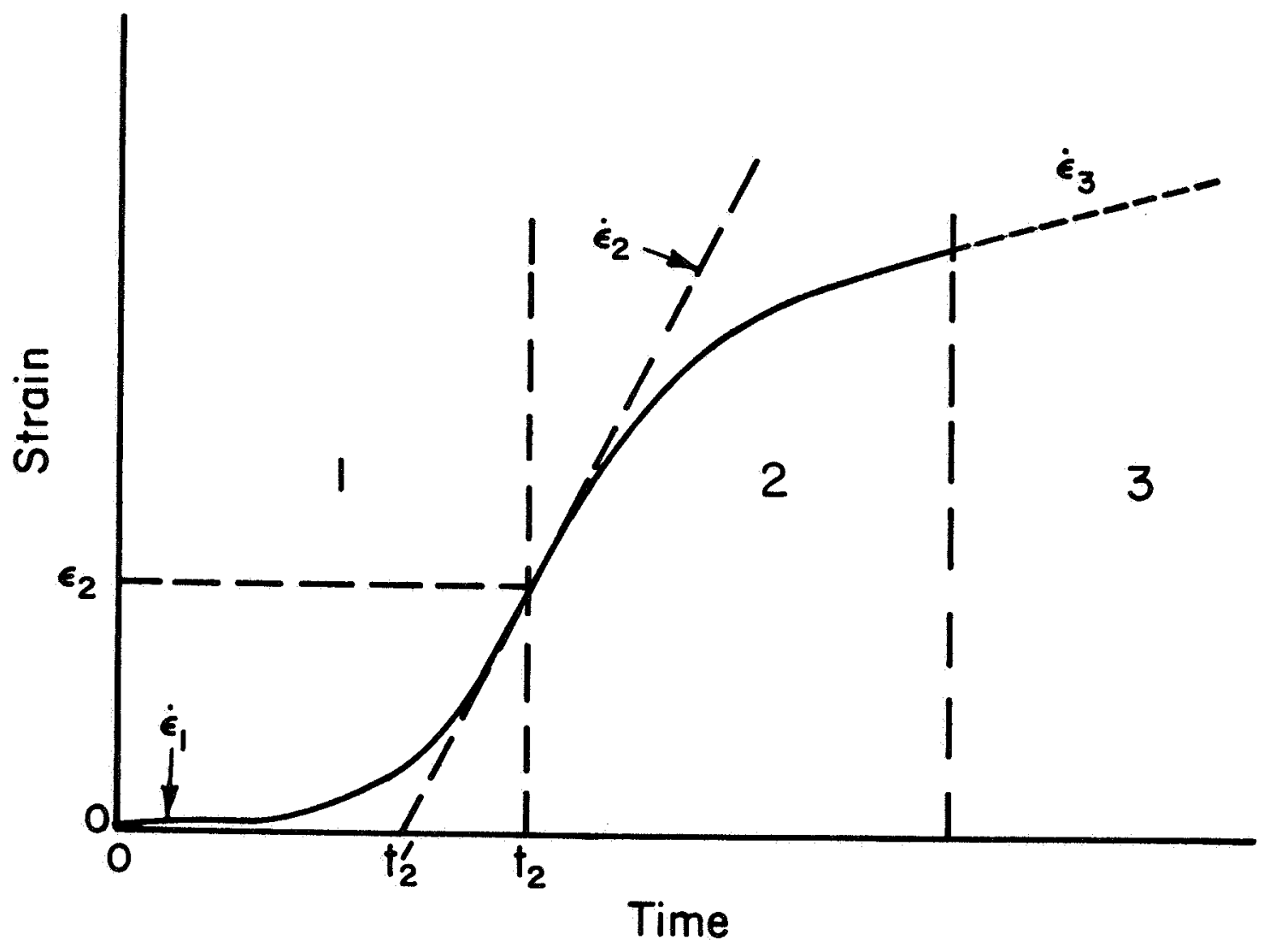

Figure 3. Schematic of a Typical Compression Creep Curve of CoO Single Crystals Having a <100> Compression Axis. Stages 1 and 2 were actually observed in creep tests. See text for discussion of Stage 3 . 


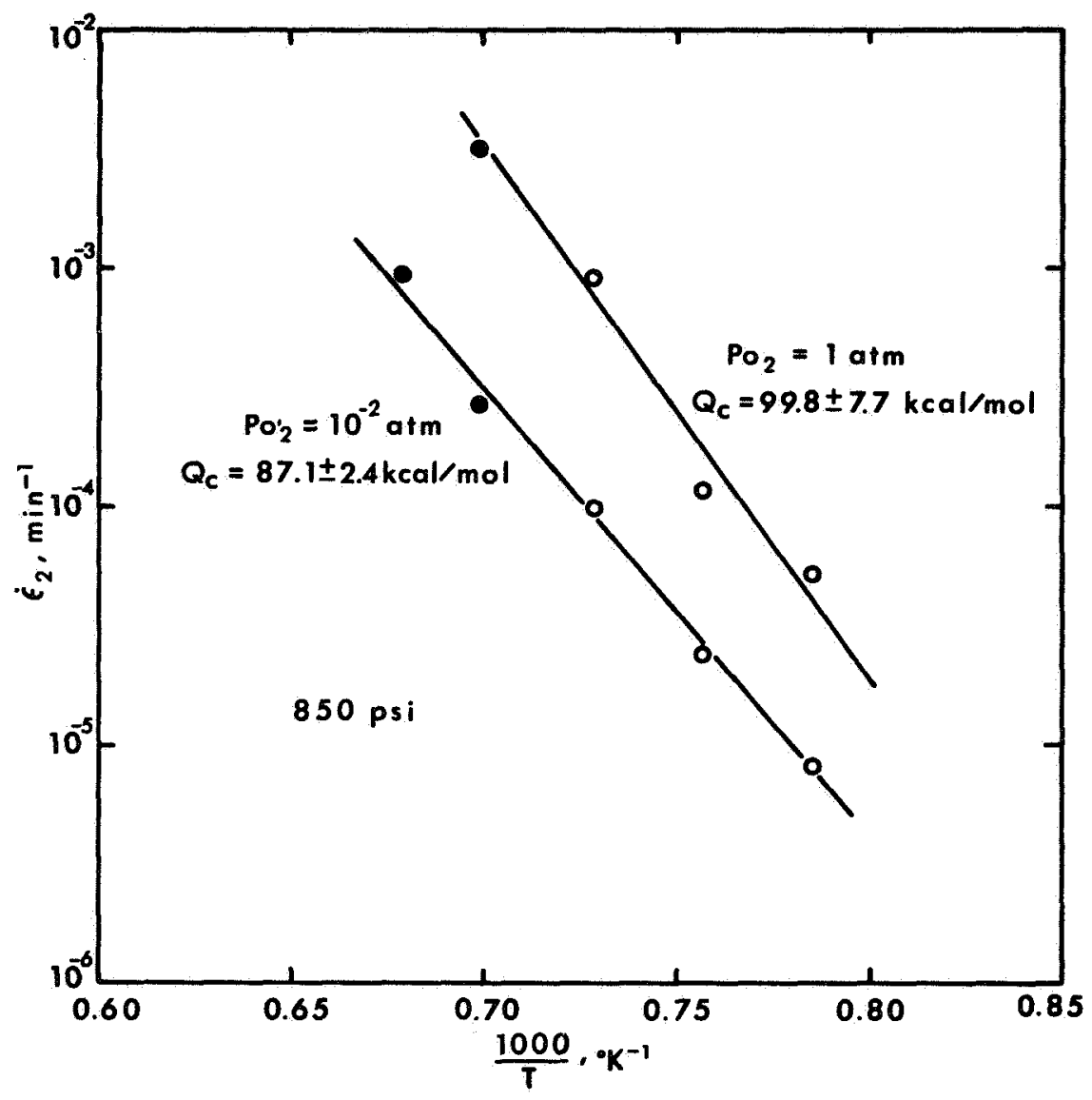

Figure 4. Temperature Dependence of $\dot{\varepsilon}_{2}$ at Two Oxygen Pressures 


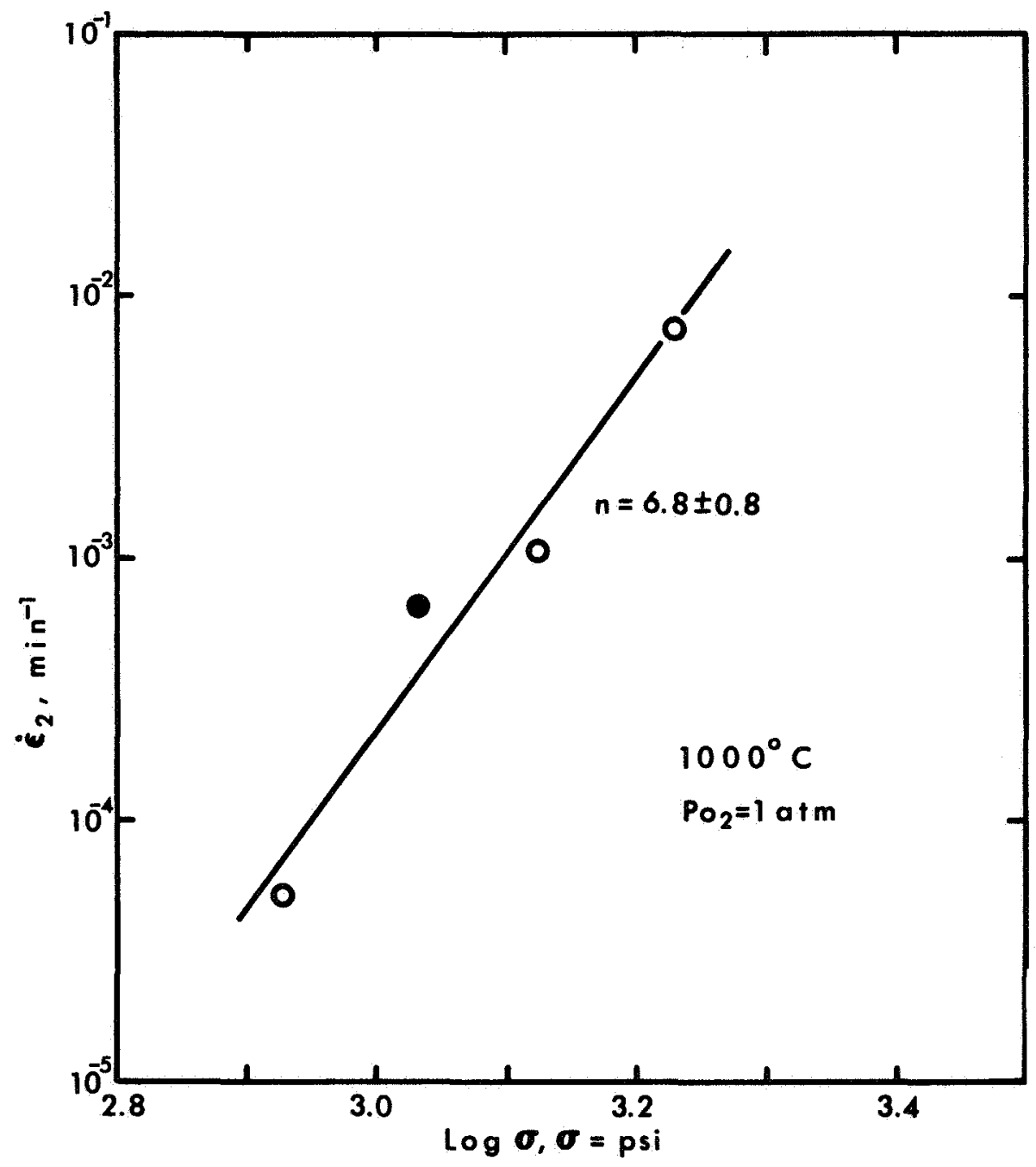

Figure 5. The Stress Dependence of $\dot{\varepsilon}_{2}$ at 1 Atmosphere of Oxygen 


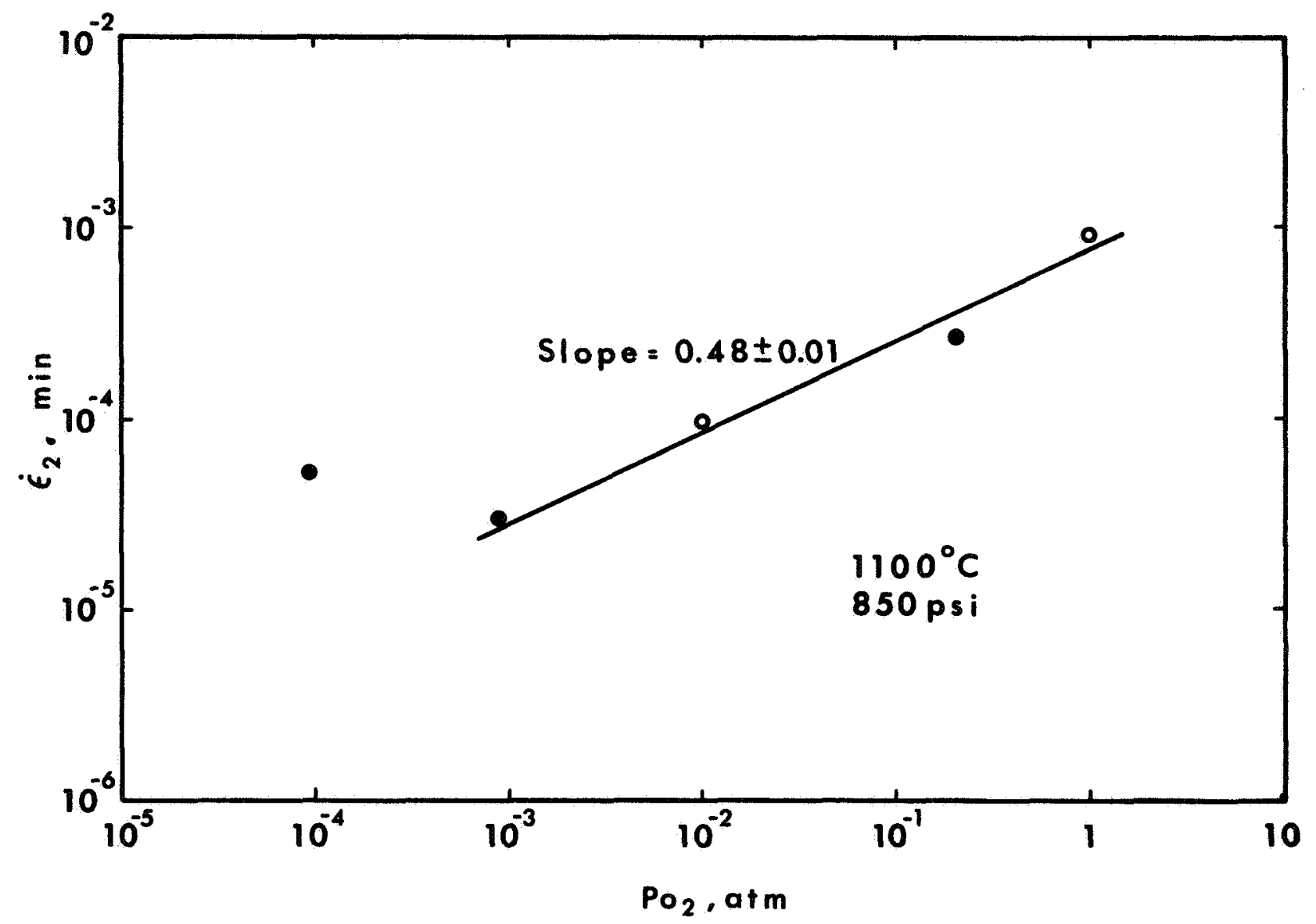

Figure 6. The Dependence of $\varepsilon_{2}$ on the Partial Pressure of ${ }^{2}$ Oxygen 


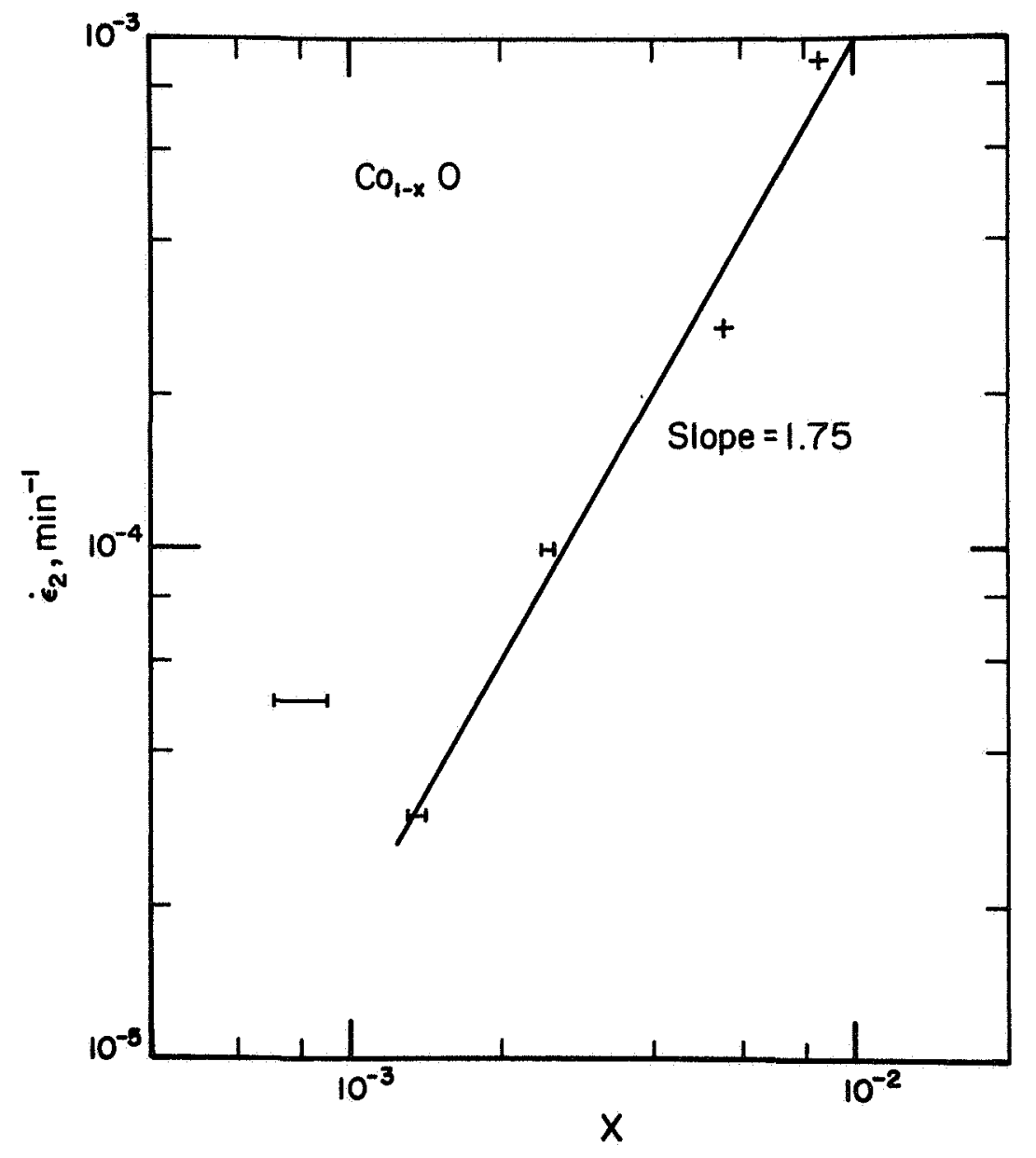

Figure 7. Composition Dependence of $\dot{\varepsilon}_{2}$ at 850 psi and $1100^{\circ} \mathrm{C}$ 


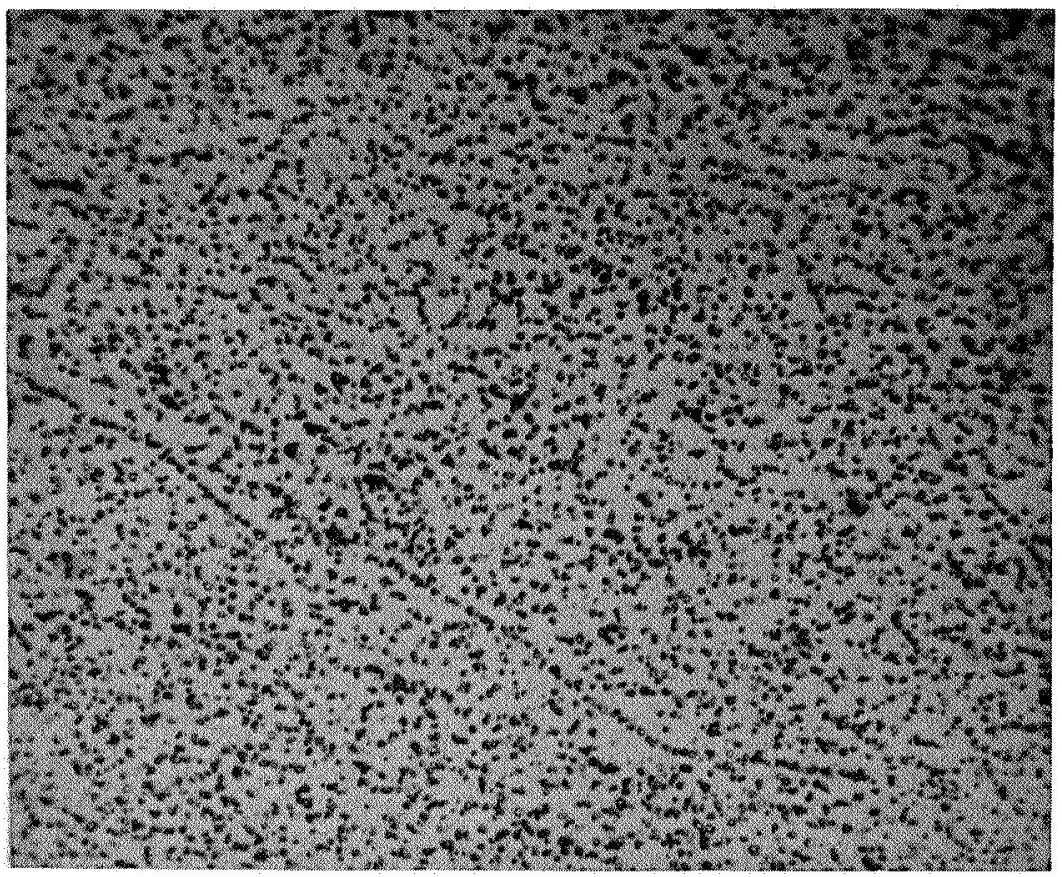

Figure 8. Precipitate Distribution in a CoO Single Crystal Annealed 66 Hours in One Atmosphere of Oxygen, Followed by a Water Quench; $850 \mathrm{X}$ 


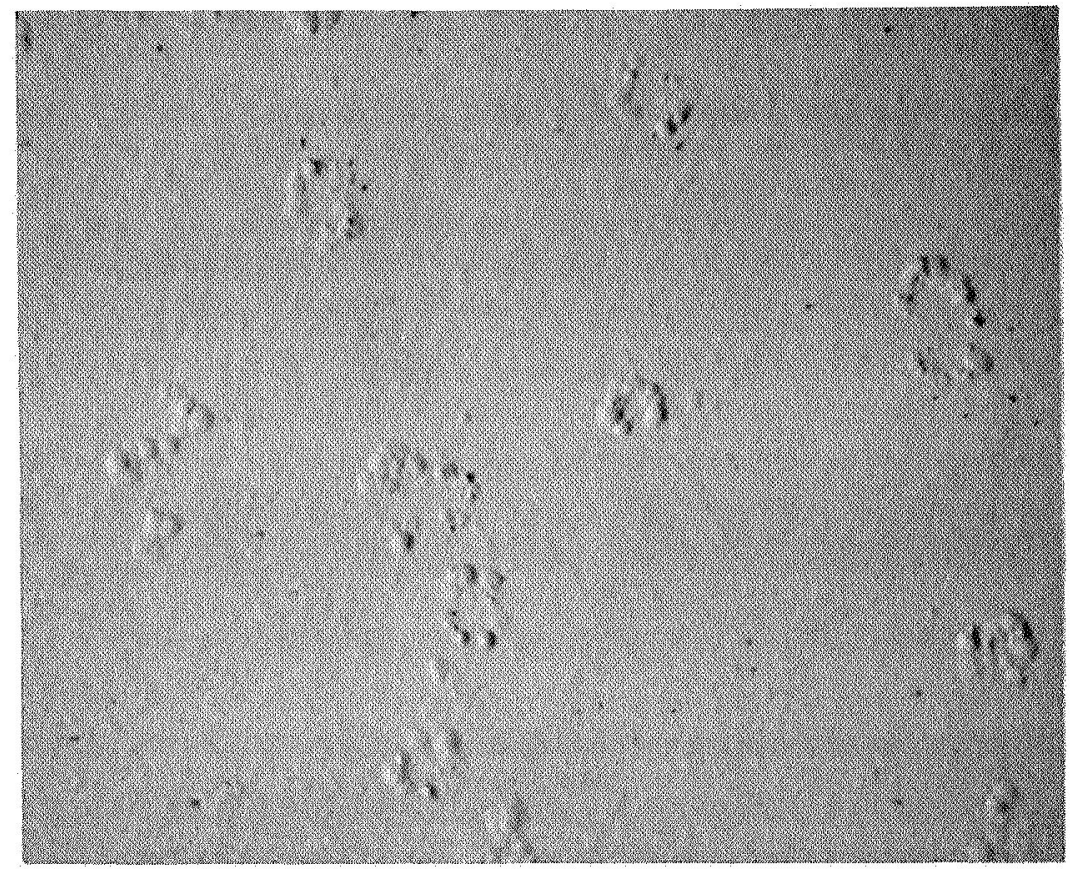

a. Near the Center of the Specimen; $1000 \mathrm{X}$

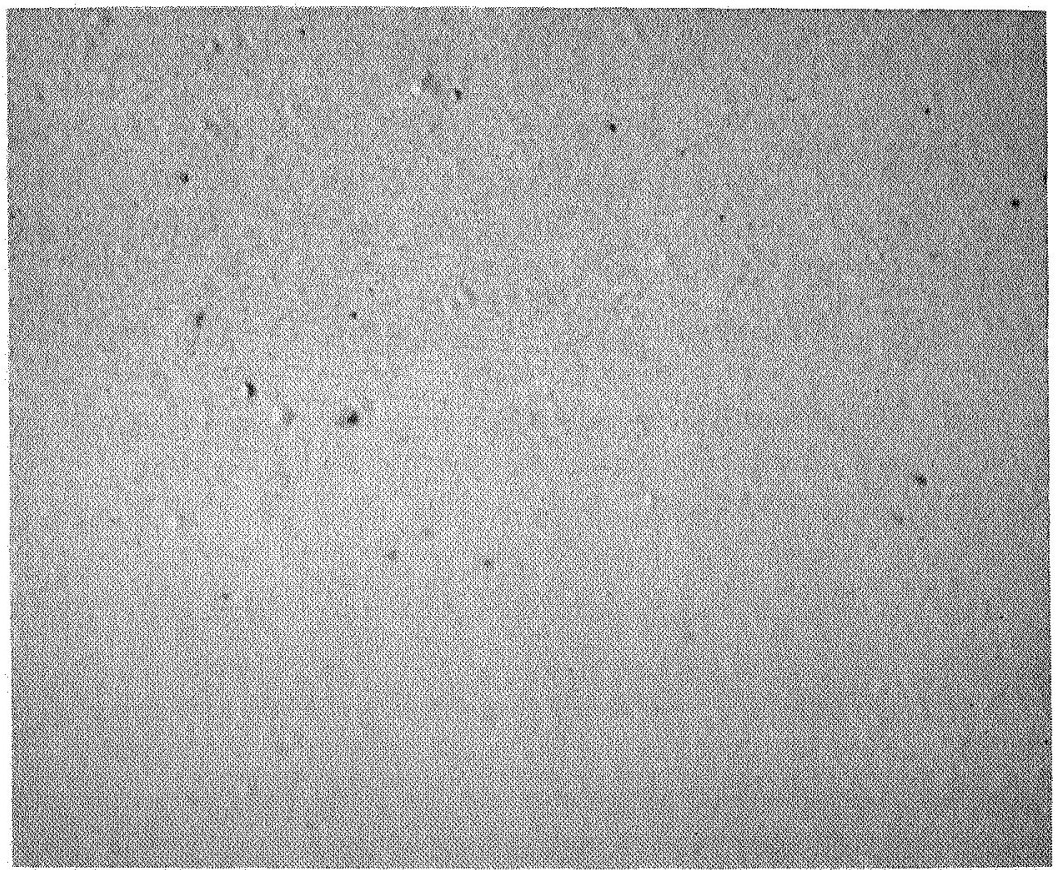

b. Near the Edge of the Specimen; $1000 \mathrm{X}$

Figure 9. Coo Single Crystal Annealed 66 Hours at $1100^{\circ} \mathrm{C}$ in an Argon-Oxygen Atmosphere having $\mathrm{p}_{\mathrm{O}_{2}}=10^{-4} \mathrm{~atm}$, Followed by a Water Quench 


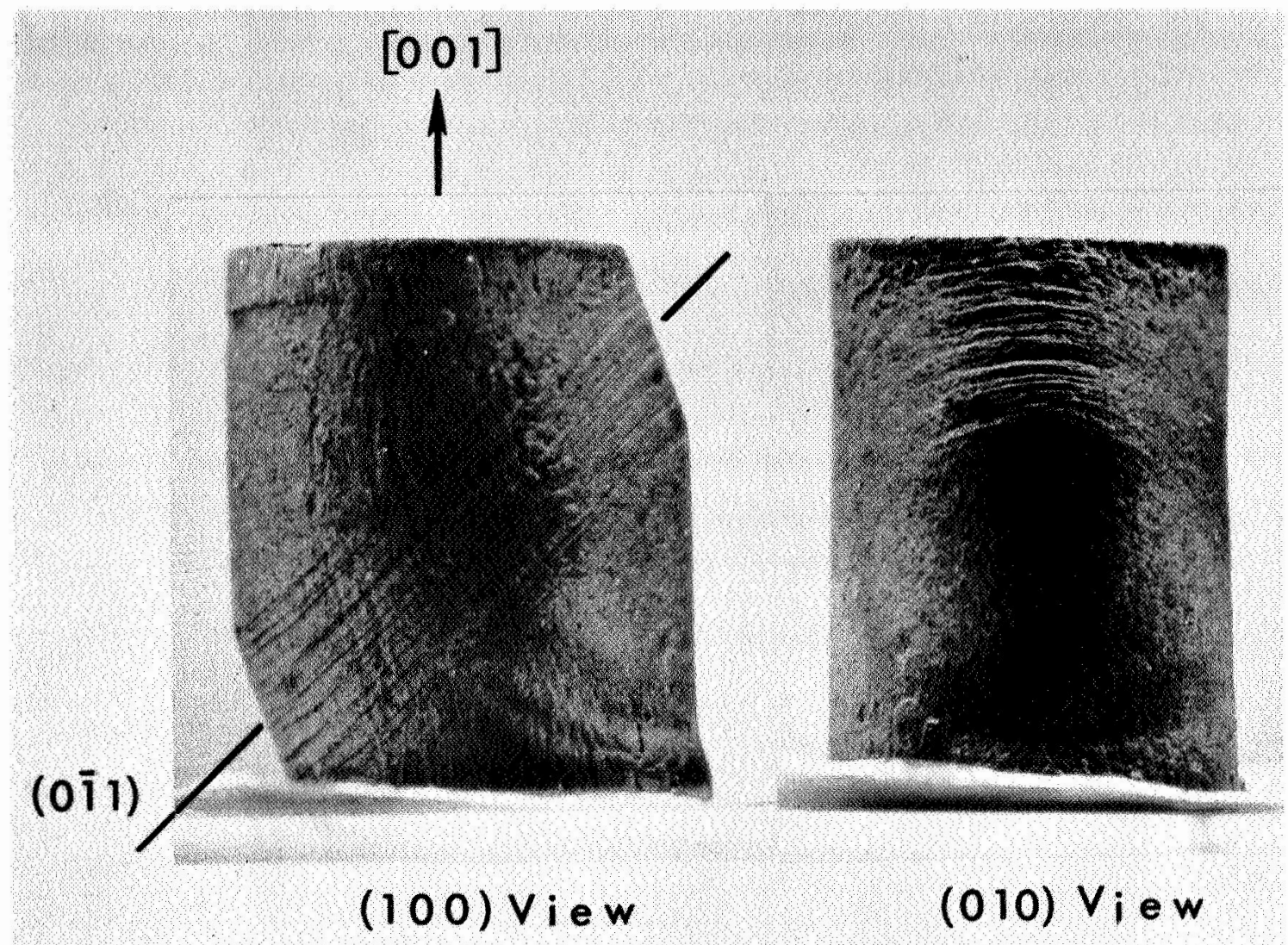

a.

b.

Figure 10. S1ip Bands on an Atypical Specimen that Deformed Predominantly by Slip on One Slip System; $9 \mathrm{X}$ 


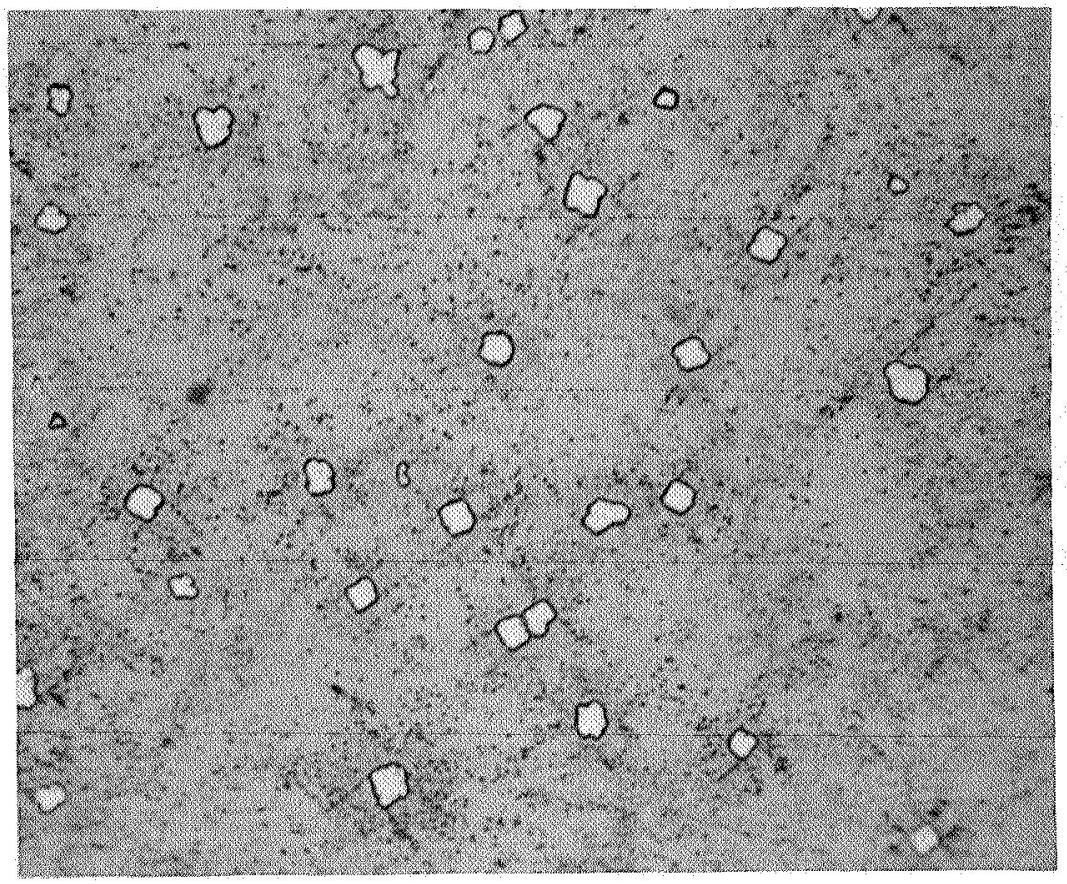

a. As-Received Microstructure of CoO Single Crystals. The white precipitates are probably $\mathrm{Co}_{3} \mathrm{O}_{4}$; polished and etched; $850 \mathrm{X}$

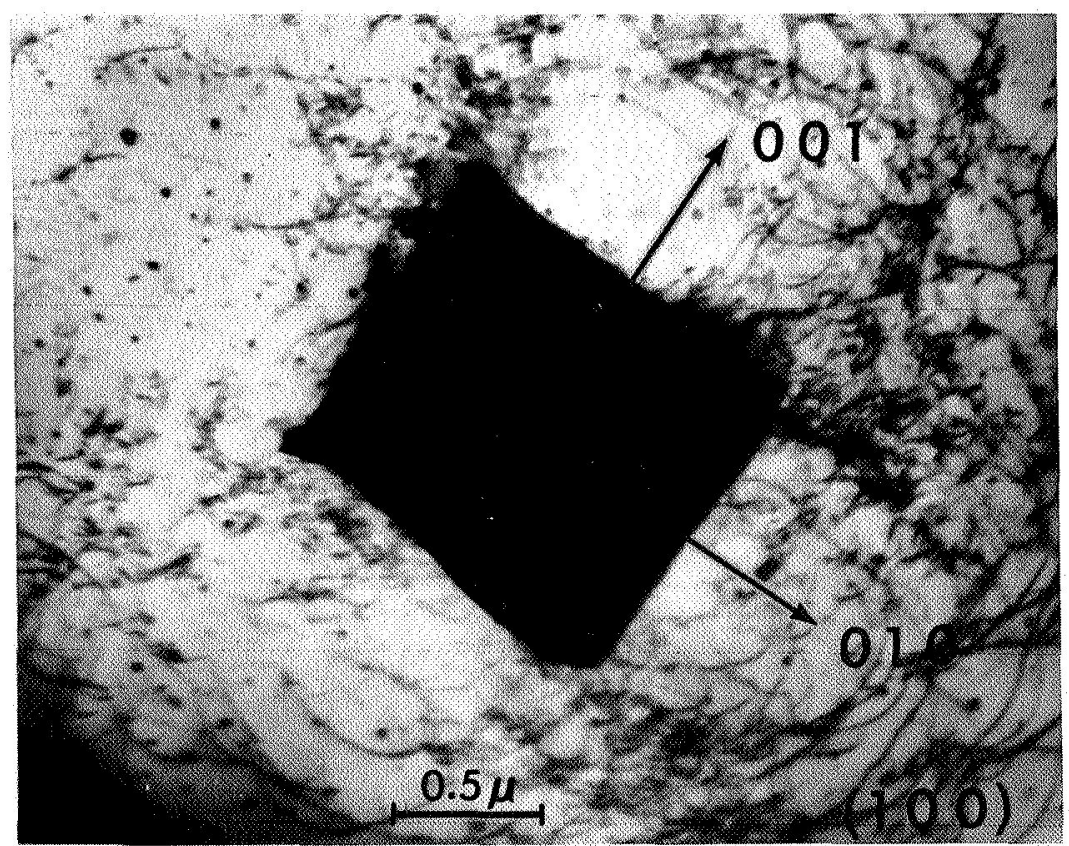

b. $\mathrm{Co}_{3} \mathrm{O}_{4}$ Particle Observed by Transmission Electron Microscopy

Figure 11. Precipitate Particles in CoO and the Dislocation Debris Associated with them 


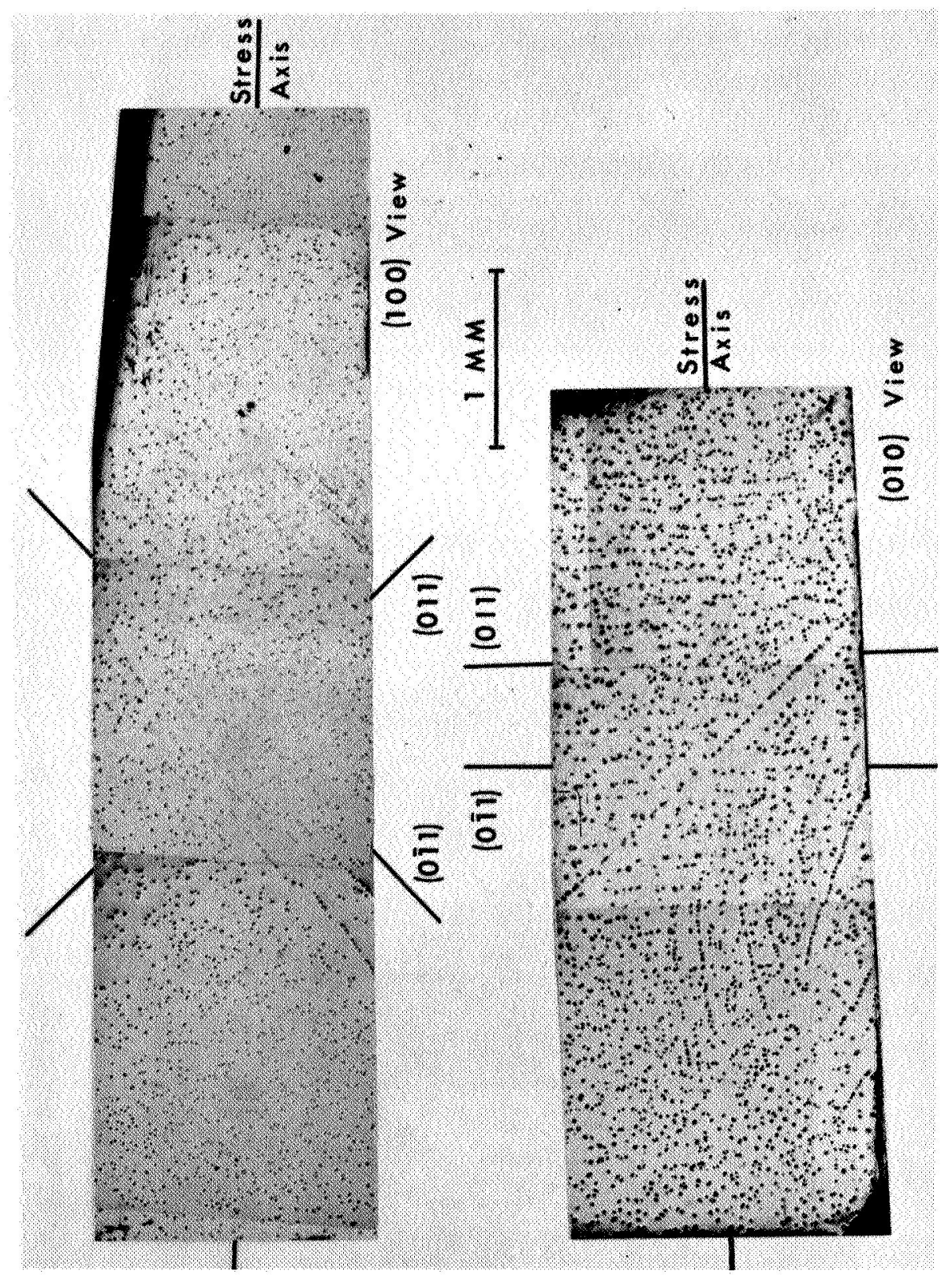

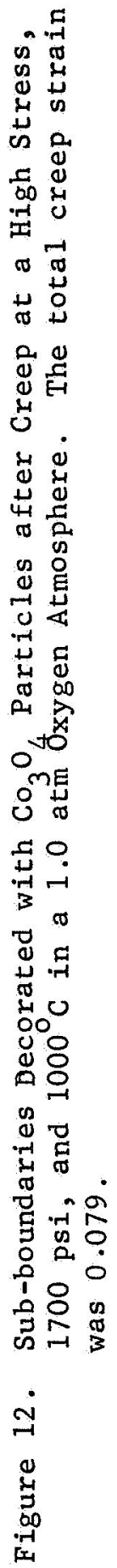




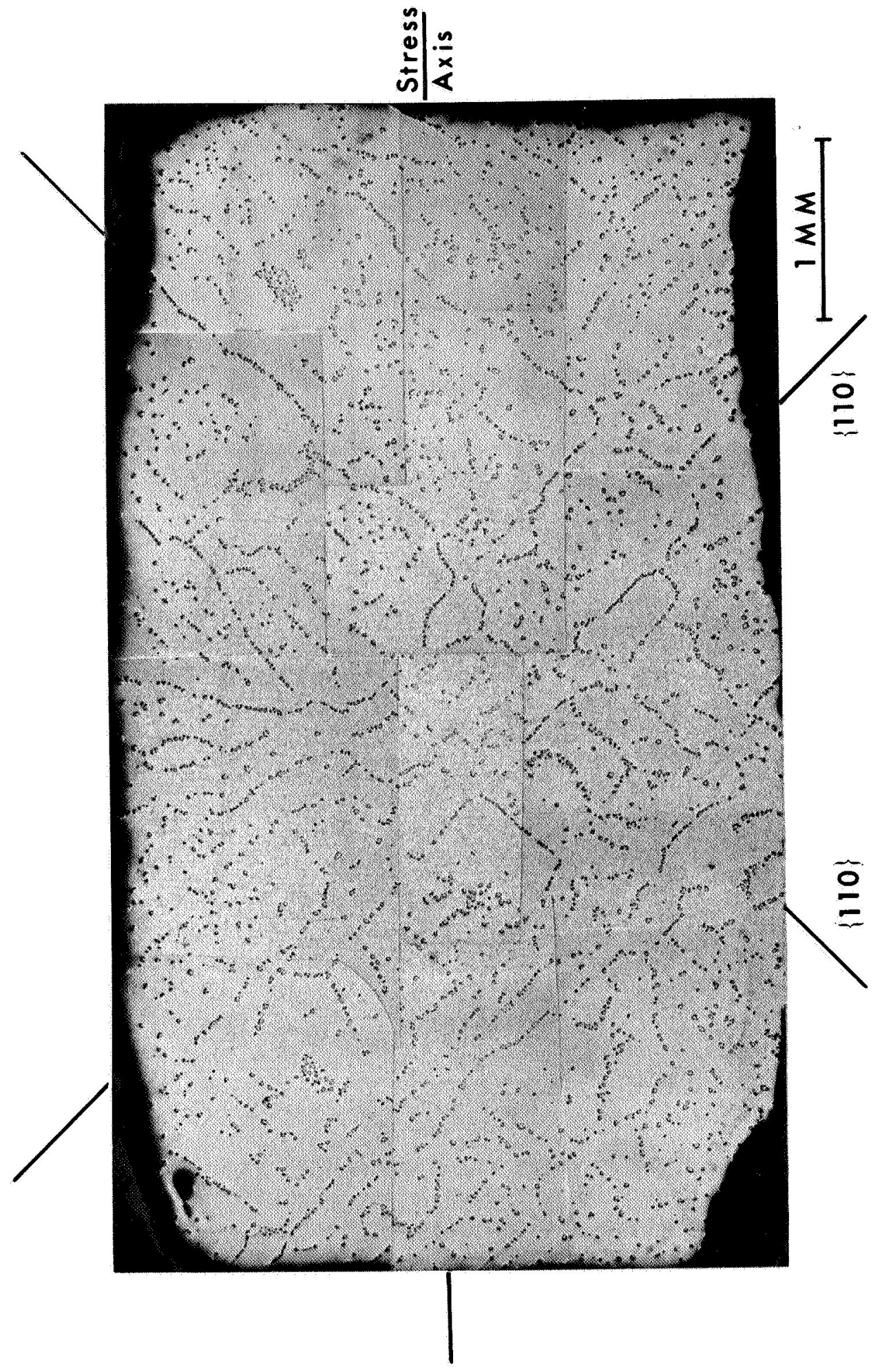

$\underset{\substack{-1 \\ 3}}{5}$

రृ 峁心 ० 8 is 㟔 어 ब i范 문 월 की फु on 3 ผ

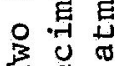
茎

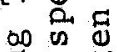
点 芩 0 皮 U 芒年

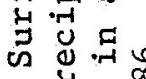
$\overbrace{}^{0}$ का 잉 $0^{\circ}$ $40 \%$

$\ddot{1}$

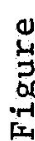




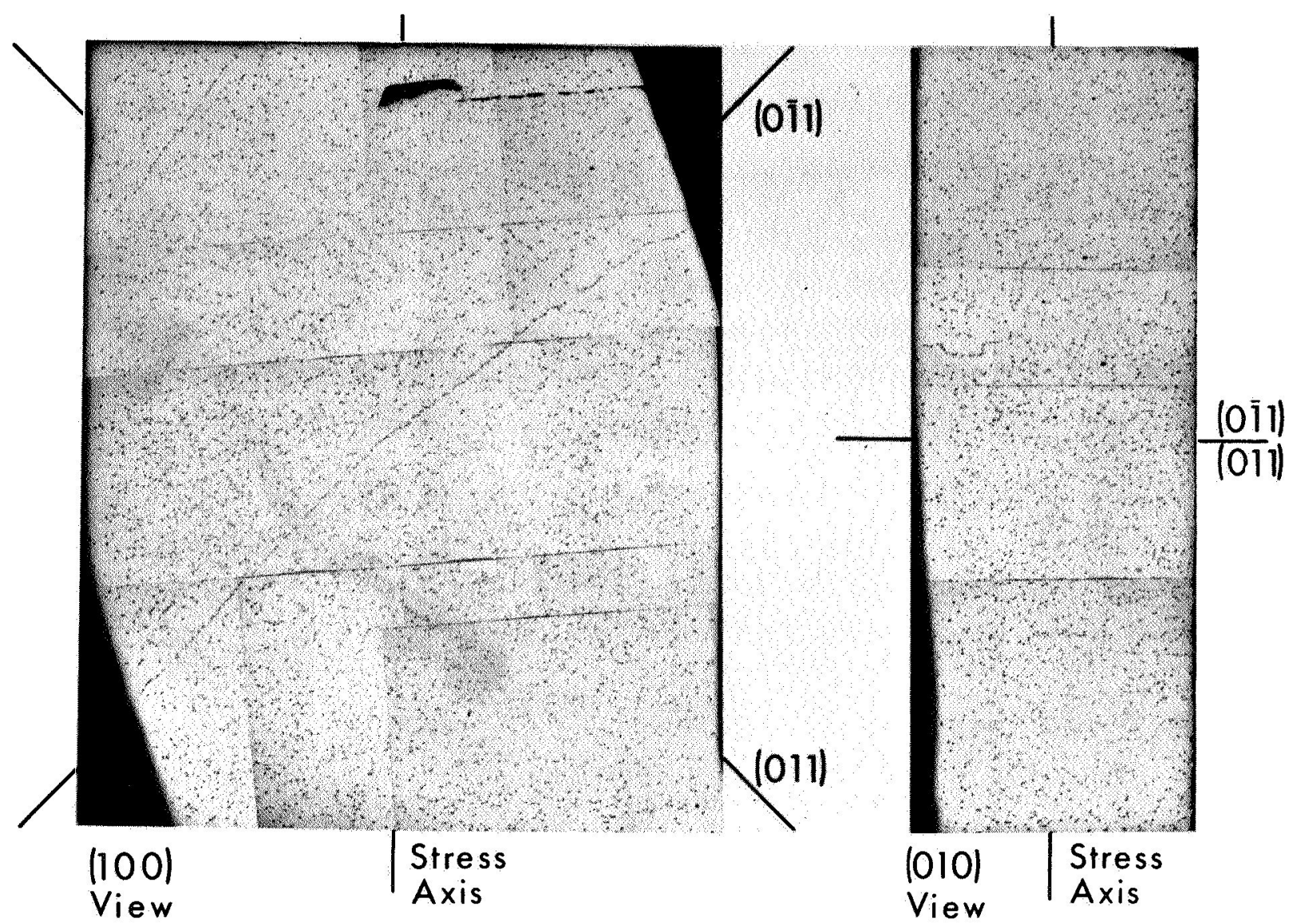

Figure 14. Polished Sections Through the Specimen in Figure 10. The precipitates do not indicate any significant pattern of substructure. 

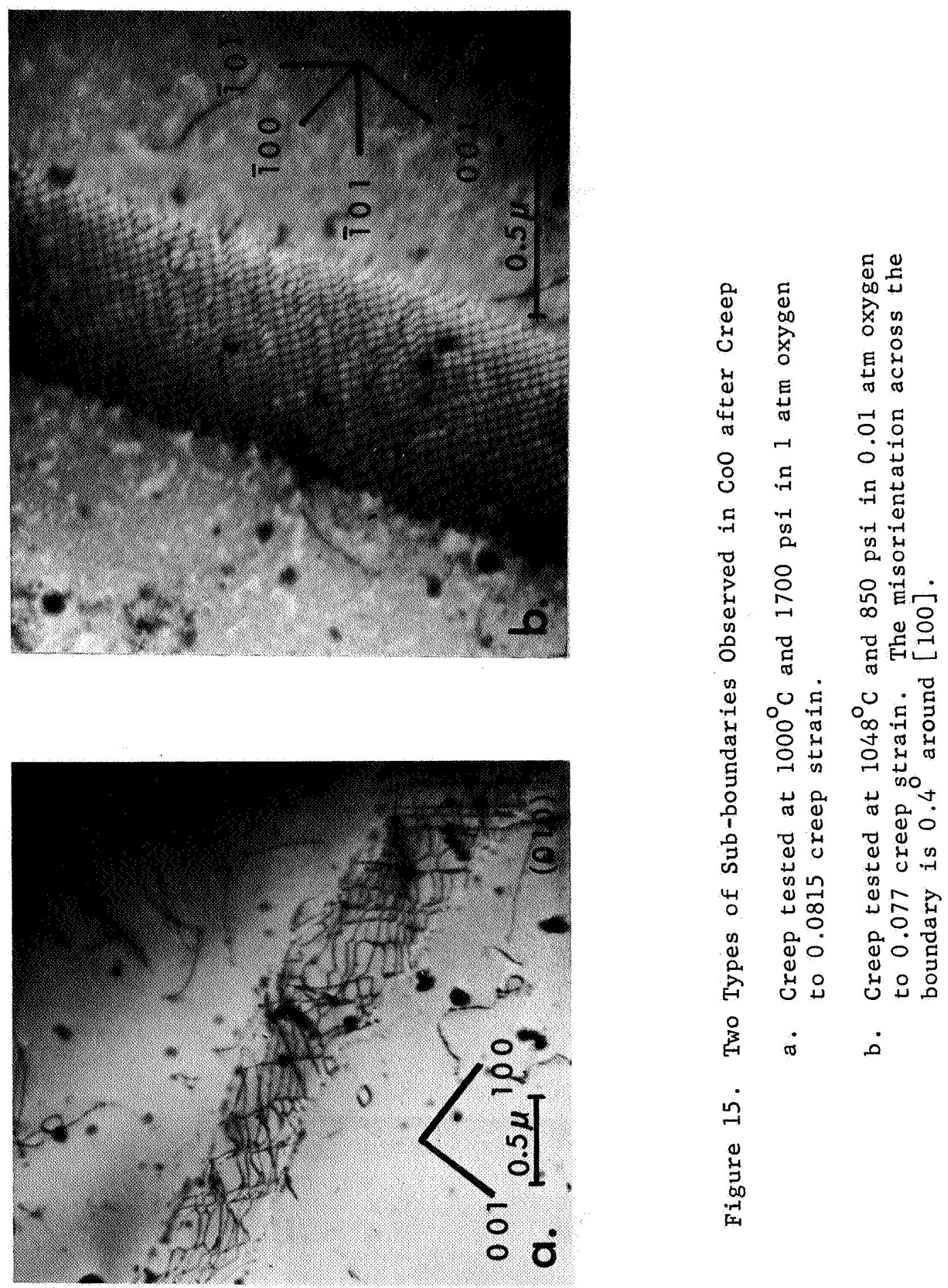


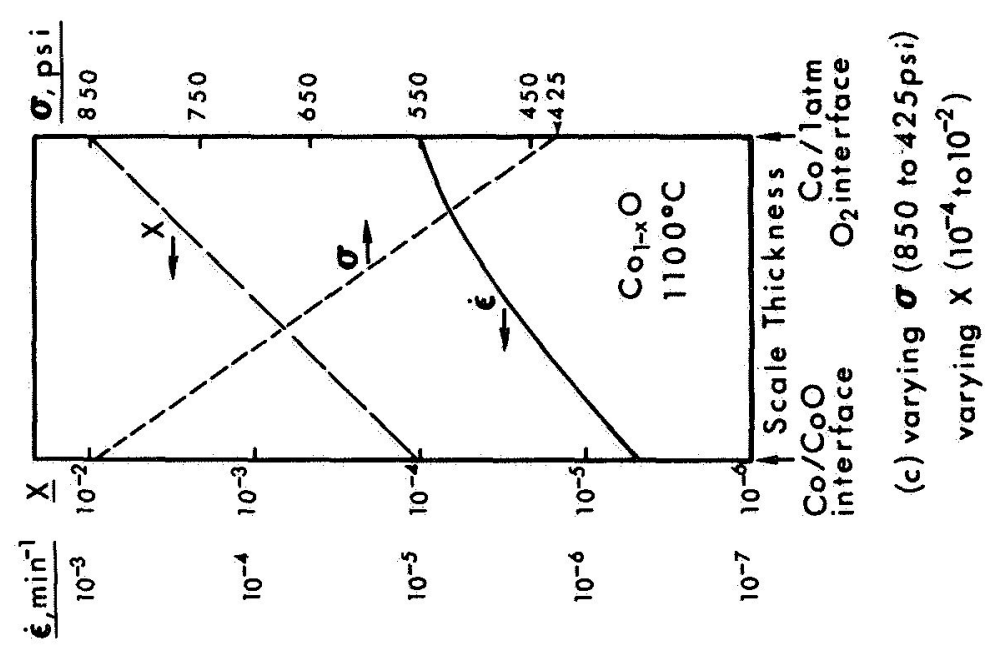

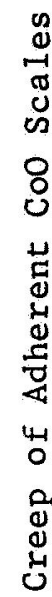
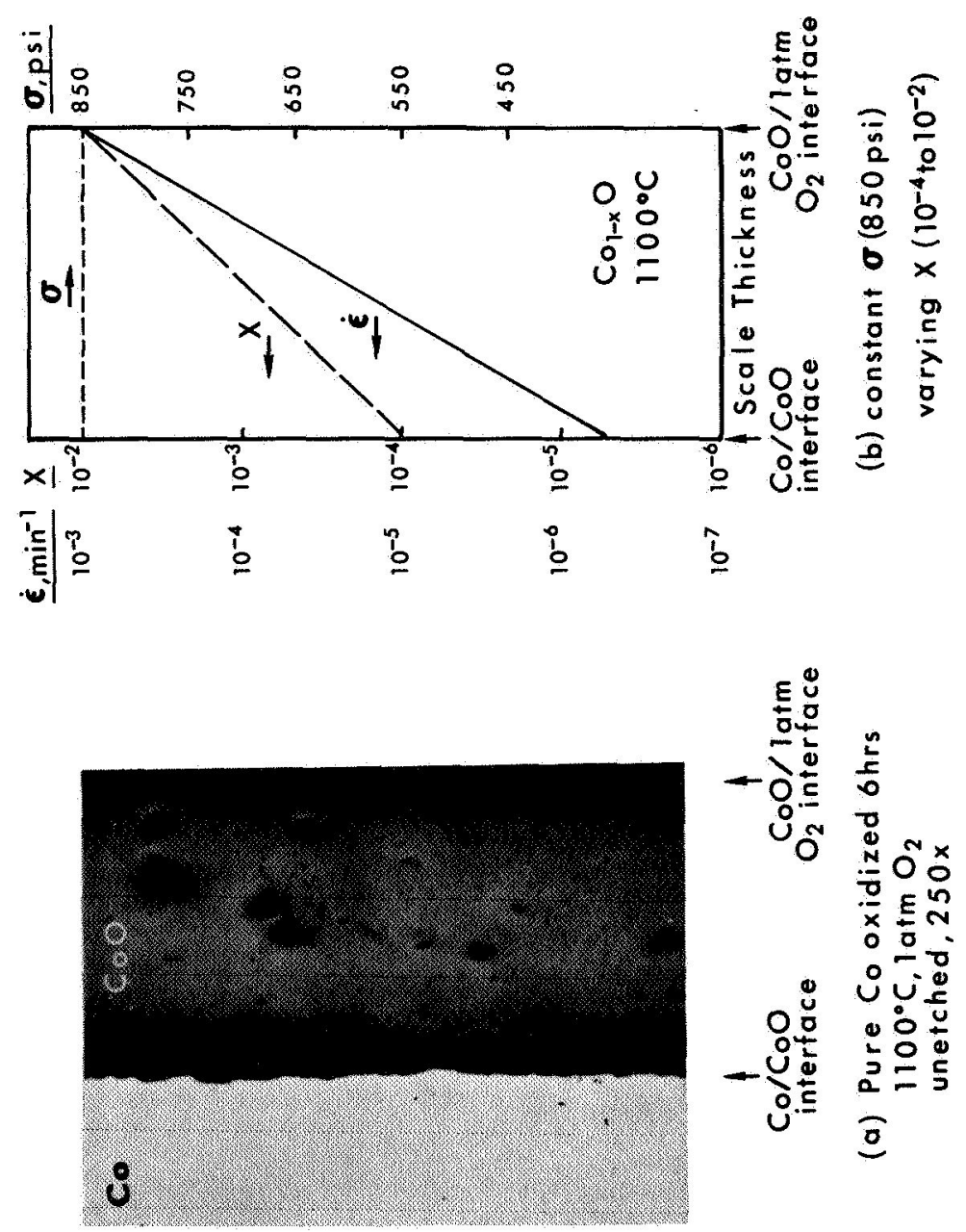
DISTRIBUTION LIST

Grant NGR-36-002-070 - Batte1le Memorial Institute

NASA Report No. CR-72420

Nationa1 Aeronautics and Space Administration

Washington, D.C. 20546

Attn: N. F. Rekos (RAP)

G. C. Deutsch (RRM)

R. H. Raring (RRM)

Winnie M. Morgan (US)

Lewis Research Center

National Aeronautics and Space Administration

21000 Brookpark Road

cleveland, Ohio 44135

Attn: G. M. Ault, M.S. -105-1 1

Technology Utilization, Office, MS -3-19

Dr. G. Santoro, MS -49-1

R. W. Ha11, MS $-105-1$

Library, MS -60-3

Report Control Office, MS -5-5

S. J. Grisaffe, MS -49-1

Dr. H. B. Probst, MS-49-1

N. T. Saunders, MS-105-1

F. H. Harf, MS $-49-1$

A. E. Anglin, MS-49-1

C. E. Lowe 11, MS-49-1

J. C. Freche, MS-49-1

C. A. Barrett, MS-49-1

Langley Research Center

National Aeronautics and Space

Administration

Langley Station

Hampton, Virginia 23365

Attn: Library

Richard Pride, MS-188A

1

\section{1}

1

1

2

1

1

1

1

5

1

1

1

George C. Marsha11 Space F1ight Center National Aeronautics and Space Adminis tration

Marsha11 Space Flight Center,

Alabama 35812

Attn: Library

1

Jet Propulsion Laboratory

4800 Oak Grove Drive

Pasadena, California 91103

Attn: Library

1
Ames Research Center

Nationa1 Aeronautics and Space Administration

Moffett Fie1d, California 94035

Attn: Library

Copies

Goddard Space Flight Center

National Aeronautics and Space Administration

Greenbe1t, Maryland 20771

Attn: Library

D. F. Hasson, Code 714

C. E. Vest, Code 249.1

1

1

1

1

Manned Spacecraft Center

National Aeronautics and Space Administration

Houston, Texas 77058

Attn: Library

N. Chaffee, EB-4

1

1

F1ight Research Center

National Aeronautics and Space Administration

P. 0. Box 273

Edwards, California 93523

Attn: Library

Federal Aviation Agency

800 Independence Avenue, SW

Washington, D. C. 20553

Attn: Brig. Gen.J. C. Maxwe11 1

F. B. Howard, SS $/ 210$

Atomic Energy Commission

Washington, D. C. 20545

Atn: Technica1 Reports Library 1

Jules Simmons

Department of Air Force

Office of Scientific Research

1

Propuls ion Research Division

Washington, D.C. 20525

Headquarters

Wright-Patterson AFB, Ohio 45433

Attn: MAAM: Technical Library

AFSC-FTDS

SESOS: J. L. Wilkins 1

MAMP: I. Perlmutter 1

AFML: $\mathrm{Dr}$. A. M. Love lace 1 
Department of the Navy Office of Naval Research Code 429

Washington, D.C. 20525 Attn: Dr. R. Roberts

Chief, Bureau of Naval Weapons Department of the Navy

Washington, D.C. 20525

Attn: T. F. Kearns

U.S. Army Aviation Materials Laboratory

Fort Eustis, Virginia 23604

Attn: John White, Chief, SMOFE-APG

Army Materials Research Agency Watertown Arsena1

Watertown, Massachusetts 02172

Attn: S. V. Arnold, Director

American Society for Metals

Metals Park

Nove1ty, Ohio 44073

Attn: Dr. Taylor Lyman

Defense Ceramics Information Center (DCIC) (1)

Batte1le Memoria1 Institute

505 King Avenue

Columbus, Ohio 43201

The Bendix Corporation

Research Laboratories Division

Southfield, Michigan 48075

Attn: C. B. Sung

1

Boeing Company

P. 0. Box 733

Renton, Washington 98055

Attn: W. E. Binz, SST Unit Chief

Genera1 Electric Company

Advanced Technology Laboratory

Schenectady, New York 12305

Attn: Library

Genera1 Electric Company

Materials Development Laboratory Operation

Advance Engine and Tech. Department

Cincinnati, Ohio 45215

Attn: L. P. Jahnke

1
Copies General Motors Corporation

Al1ison Division

Indianapolis, Indiana 46206

Attn: D. K. Hanink, Materials

Copies

$$
\text { Laboratory }
$$

Internationa1 Nicke 1 Company

67 Wa11 Street

New York, New York 10005

1 Attn: R. R. Dewitt

1

International Nicke1 Company

P. D Merica Research Laboratory

Sterling Forest

Suffern, New York 10901

Attn: Dr. F. Decker

1

Lockheed Palo Alto Research

Laboratories

Materials and Science Laboratory $52-30$

3251 Hanover Street

Palo Alto, California 94304

Attn: E. C. Burke

1 Narmco Research and Development Division

Whittaker Corporation

3540 Aero Court

San Diego, California 92123

Attn: Dr. F. J.Rie1, Technical

Director

The Ohio State University

Columbus, Ohio 43210

Attn: Professor M. G. Fontana, Chairman

Department of Meta11urgica1 Engineering

Solar Division

1 Internationa1 Harvester Corporation San Diego, California 92112

Attn: J. V. Long, Director of Research

1 Stanford University

Palo Alto, California 94305

Attn: Prof. Oleg Sherby

Department of Materials Science 
United Aircraft Corporation

Copies

400 Main Street

East Hartford, Connecticut 06108

Attn: E. F. Bradley, Chief

Materials Engineering

University of California

Los Angeles, California 90024

Attn: Dr. G. Hoffman

Tem-Pres Research, Inc. 1401 South Atherton Street

State College, Pennsyivania 16801

Department of Metallurgy

UCLA

Los Angeles, California 90024

Attn: Dr. D. I. Douglass

Genera1 Electric Company

Materials Development Laboratory Operation

Advance Engine and Tech. Department

Cincinnati, Ohio 45215

Attn: C. S. Wukusick

The Ohio State University

Columbus, Ohio 43210

Attn: Dr. A. R. Rapp

Department of Metallurgical

Engineering 